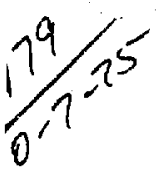

$\theta 2-1664$

UCRL-51872

\title{
THE DESIGN OF A REPETITIVELY PULSED MEGAJOULE DENSE-PLASMA FOCUS
}

\author{
O. Zucker \\ W. Bostick \\ R. Gullickson \\ J. Long \\ J. Luce \\ H. Sahíin
}

August 1, 1975

Prepared for U.S. Energy Research \& Development Administration under contract No. W-7405-Eng-48
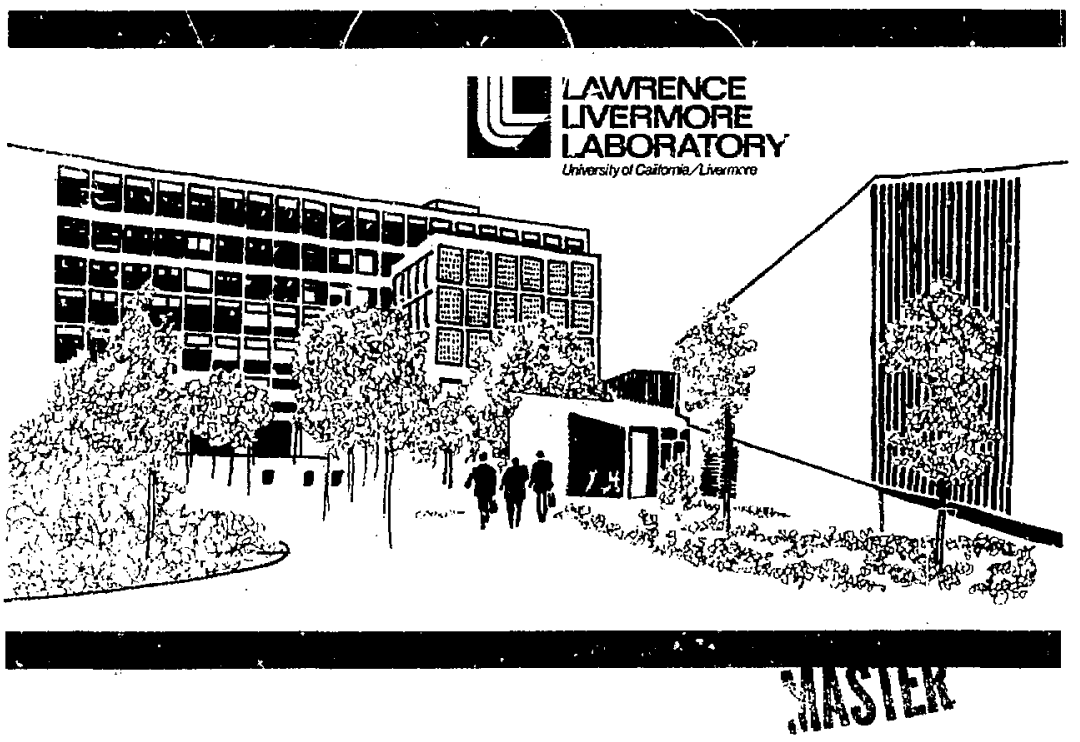


\section{NOTICE}

"This report was prepated as an account of work sponqured by the Uniled States Government. Neither the United States nor the United States Energy Research se Development Administratiou, not any of their employess, nor any of their contractors, subcontractors, or theit employees, makus any wairanzy. express of implied, or assumes any legal linbility or tesponsibility for the aecuracy, contpleteness or usefulness of any information, apparstus, product os process disclosed, or tepresents that its use would not infringe privately-owned rights."

Printed in the United States of America Available from

National Technical Information Service

U,S. Department of Commerce 5285 Port Royal Road Springfield, Virginia 22151 Price: Printed Copy $\$$ *; Microfiche $\$ 2.25$

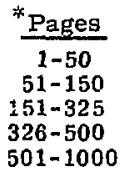

NTIS Selling Price

$\$ 4.00$

$\$ 5.45$

$\$ 7.60$

$\$ 10.60$

$\$ 13.60$ 


\title{
近 \\ LAWFENCE LNERMOFE LABORATORY \\ Utriversity cl Calitomia Livermore, Cahtonia/94550
}

UCRL-51872

\section{THE DESIGN OF A REPETITIVELY PULSED MEGAJOULE DENSE-PLASMA FOCUS}

\author{
O. Zucker \\ W. Bostick \\ R. Gullickson \\ J. Long \\ J. Luet. \\ H. Sahlin
}

MS. date: August 1, 1975

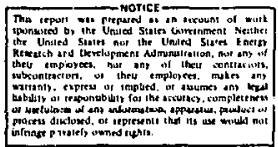




\section{Contents}

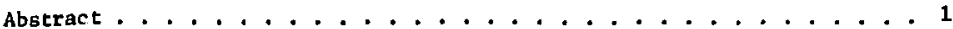

Introduction ........................ 1

General ........................ 1

Design Considerations ................ 3

Electrical-Energy Requirements for Neutron-Test Facilities . . . . . . 4

Design Criteria for the SFG Pulsed Materialg-Testing Device ...... 8

Required Yleld for Rapld Pulsing .............. 8

Energy Coupling to Plnch ................. 15

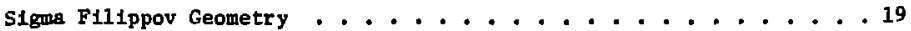

Inductance Time-Dependency .............. 19

Low InItial Current Density . . . . . . . . . . . 22

Large Target Area and Plasma-Focus Accessibility . . . . . 22

Cooling ................... 23

Shielding .................... 25

stepped Inductor . . . . . . . . . . . . . . 25

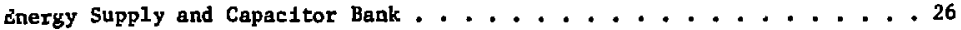

Introduction . . . . . . . . . . . . . . 26

The Capacitor Bank . . . . . . . . . . . . . . . 27

Foil Geometry aná Corona Reduction ............. 27

Capac1tor-Section Degign and Cooling Congiderations . . . . . 28

Inductance Considerations and Current Crowding . . . . . . 32

Power Source and Charging Circult .............. 40

switching ....................... 40

Research and Development ................... 45

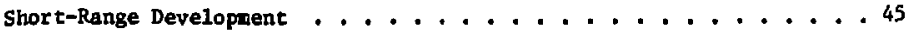

High Voltage Operation of the SFG . . . . . . . . . 46

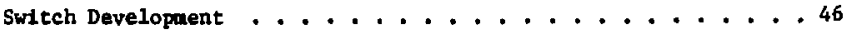

Long-Ljfa Capacttor Bank . . . . . . . . . . . 46

Electrode Eroston . . . . . . . . . . . . 46

Long-Range Regearch ... . . . . . . . . . . 46

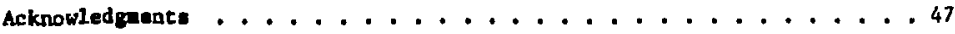

Referencen ........................ . . 48

Appendix A - Eetionation of Internal Stored Magnetic Energy In a

Circular Vane Structure ................. 49

Appendix B - Origin of Temperature-Rial Dependence . . . . . . . . 54 


\title{
THE DESIGN OF A REPETITIVELY PULSED MEGAJOULE DENSE-PLASMA FOCUS
}

\begin{abstract}
This report describes a 1 pulse average power consumption, which has per second, dense-plasma-focus (DPF) materlals-testing device capable of delivering a minturum of $10^{15}$ neutrons per pulse. Moderate scaling up from existing designs is shown to be sufficient to provide $2 \times 10^{13}$ neutrons/ $\mathrm{cm}^{2}$. s to a suitable taryet. The become a major issue due to the energy crisis, is analyzed with respect to other plasma devices and is shown to be highly favorable. Also discussed Is a novel approach to capacitor-bank and switch design with respect to repetit Ive-pulse operation.
\end{abstract}

\section{Introduction}

GENERAL

To produce a practical design for controlled-thermonuclear or laserfusion reactors, it is necessary to assume that some structural members will be irradiated by a high flux of $14 \mathrm{MeV}$ neutrons in addition to a "plasma wind" containing gamm-rays, $x$-rays, ions and electrons. Thus, a necessary preliminary to any final design must be the test and evaluation of the structural materiale that w11 be exposed to this hostile radiation environment. He propose to satisfy lixe neutron-source requirements for materials testing with a one-megajoule dense-plasma-focus (DPF) system designed to deliver one $10^{15}$ DT reutron burst per second. (A similar facility sponsored by Euratom for fusion-reactor materials testing is being considered for a joint European plasma-focus effort at Frascati.) The design of the onemegajoule system described in this report offers unique solutions to high-voltage, energy-storage and switching problems for a repetitively puised system. It is suggested that the tec mology described herein can lead to the building of flasma foct in the multi-megajoule range. The design of the proposed system Is based on a one-megajoule nonrepe-titive DD plasma-focus device now being constructed in the Physics 
Department at Lawrence Livermore laboratory (LLL). This machine, which is jointly funded by ERDA and the Defense Nuclear Agency (DNA), has been given the generic name of Sigma Filippov Geometry (SFG). Because of its efflciency and realistic plasmawind environment, we suggest that the plasma focus simulator herein proposed can be considered as a device for testing materials to be used in both pulsed laser, DC and quasi DC fusion reactors.

Some salient advantages of the SFG simulator are:

- The plasma focus is at the present time unequaled as a laboratory pulsed-neutron source.

- Because of its appraximate $\mathrm{E}^{2}$ scaling and hightemperature, high-density plasma and point-source characteristics, the SFG simulator should be basically more efficlent than other proposed highenergy fusion-reactor simulatore. (E is the atored energy of the plasma focus.) Thts should be an important consideration during the next few years when considering the energy crisis and the power requirements of alternative systems.
- Tile goals set for the SFG simulator should be attained without any new of fundamental advance in physics. However, considerable development work w111 be required.

- Ar R\&D program almed coward fundamental improvenents may lead to incre ased yieldo in the range of $10^{16}$ to $10^{17}$ DT neutrons per pulse.

- In common with other plasma simulators the proposed device provides a realistic environment which includes gamma-rays, x-rays, electrons and lons as well as neutrons. Th1s plasma wind is not provided by present or proposed bean-target systems.

- Because of Its Large electrode surface area and special geometry, the proposed SFG simulacor is easy to cool and provides better radiation areas and easler access than other plasmafocus devices.

The high demonstrated efficiency and small source dimensions of the SFG simulator are major positive considerations. Unless proposed DC and quas1-DG large ourface-area Bources significantly improve their efflcler.cy (near eclentiflc breakeven), 
I heir power consumption will be in the hundreds or thousands of megawatts in order to achleve the requirad flux levels. Even if such power demands can be met, (an unllkely posslbility considering the energy crists and the gloomy energy projections for the $1980^{\prime}$ s) the ut 111 ty bill for the operation of these devices will be unreasonably high. However, due to the high efficlency and small source size, the neutron flux requirement can be met using the LIPF at a small fraction of these costs.

It is assumed that there will be a need for matcertals testing in the immediate future. This requirement has influenced us to limit our proposil 1 to a simulator design based on the one nepajoule nonreperitive plasma-focus device now under contt ruction in the lll, Physics Iheportment .

DESIGN CONSIDERATIONS

$T !$ - SFG device currently being constructed at LLL is echeduled to becone operat 'onal in mid 1975. During the ensuing year it should achleve an operational level of $>10^{13}$ DD neutrons per pulse. This yleld Is equivalent to a DT yield of $>10^{15}$ neutrons. The pulse width for this high-energy system is expected to be nominally about $100 \mathrm{~ns}$. However, it must be recognized that the high-space-resolution and timeresolution measurements of the Stevens group ${ }^{1}$ show that the broader neutron and $\mathrm{x}$-ray pulses (about $\mathrm{I} 00 \mathrm{~ns}$ ) are really made up of a superposition of a number of short pulses, each of which is about $10 \mathrm{ng}$ long, or less. Thus the actual neutron and $x$-ray irradiation of a sample which is a few centimeters from the plasma focus is in the form of very short pulses, each one of which is a fairly good simulation of the neutron pulse from a laser fusion devica. For tgesting the effect of $14 \mathrm{Me}$ " neutrons on the bulk of structural materials it is very likely that the accumulated neutron fluence rather than the peik flix is the important factor. Therefore this $1 \mathrm{MJ}, 1 \mathrm{pps}$ (pulse per second) plasma focus ran also very likely be a suicable simulatcr for DC and quasi-DC reactors. This plesma focus could also be operated at 60 pps at $150 \mathrm{~kJ}$, if so desired.

The design oelected for the nonrepet Itive SFG davice now under conatruction eliminates all cables by wounting plasma focus components directly on flat transmisuion-line plates. This design avoids the damage that occurs when nigh-voltage transients encounter high impedance at cable connections. A $100 \mathrm{~kJ}$ plasma- 
focus device which incorporates this feature has been in operation at LLL for $11 / 2$ years. It has proved the srindnese of the untque cable-1ess iesign we plan to use in the Sirg fusion-reactor simulator.

It is important to note that the success of this profect depends on straight forward technological extrapolation of well-known plasma-focus and electrical engineering parameters. Present plasma-focus devices are designed for intermittent operation which 1 imits tuem to about 100 shuts per day. Thus, a major milestone In butlding a materials-testing neutron source is the building of a suitable repetitively-pulsed capacitor bank. The development of long-1 I ved electrical components for the repetitive syatem does require considerable innovative engineering and development work. It ems which aust be considered include long-lived switches, capacitors and plasma-focus components.

\section{Electrical-Energy Requirements for Neutron-Test Facilities}

A major consideration in the evaluation of a fusion simulator is

its electrical-powe: requirements. This section is a review of the energy requirements for plasma driven devices. The effictency of accelerator beatn-target gystems are relat ively well-known and will not be diacussed.

The energy release of $17 \mathrm{MeV}$ due to one JT fusion is $2.8 \times 10^{-12} \mathrm{~J}$, The energy is carried of $f$ by these reaction products: a $14 \mathrm{MeV}$ neutron that does not couple to the reacting plasma, and a $3.5 \mathrm{MeV}$ a particle that may be contained in the reacting plasma and thus contributes to plasma heating. The operating power required by a
$14 \mathrm{MeV}$ neutron test facility is given by

$$
P=\frac{\phi A}{\varepsilon}\left(2.8 \times 10^{-18}\right) M W,
$$

where

$$
\begin{aligned}
& \Lambda=4-\mathrm{n}^{2} \mathrm{~cm}^{2} \\
& R=\text { the test volume radius } \\
& \frac{\text { fusion energy out }}{\text { electrical energy in }} \\
& \text { F - electric power in MW } \\
& \text { required tu operate the }
\end{aligned}
$$

If we assume $-10^{14}$ neutrons/ $\mathrm{cm}^{2}, \mathrm{~s}$, then

$$
P=\frac{A}{\varepsilon}\left(2.8 \times 10^{-4}\right) \text { megawates }
$$


The luft ial eselmate of for b-r for a planma focus operated at the I M. level is $=2.8 \times 10^{-3}$. This est imate 1 s based on experience with the largest utp operated (at Los Alamos) and the generally accepted yield tat io of 100 for $D-T$ vs D-D. If che radius $R$ of the test volume is taken as ? cm, then for the proposed pulsed-plasma-focus neutron and radiation facflfty $A=50 \mathrm{~cm}^{2}$. It should be noted that small test samples could be placed closer than $1 \mathrm{~cm}$ from the plasma-focus neutron source. The power (P) required to operate the plasma focus system with $\phi=10^{14} \mathrm{n} /$ $\mathrm{cm}^{2} \cdot \mathrm{s}, \mathrm{A}=50 \mathrm{~cm}^{2}, \varepsilon=2,8 \times 10^{-3} 1 \mathrm{~s}$ 5 s. If no improvements In present system performance are assumed. The resicarch and development program described later in this report may lead $t a$ a reduction in $P$ by a factor 2103.

To provide an estimate of operat ling-power requirements for neutron-test facilities based on various thermonuclear plasma devices we will assume that the condition $\mathrm{ni}=10^{12}$ ac $\mathrm{T}=8 \mathrm{kV}$ has been atcinined. Thin condition corregponds to a value or, 0.0 or $1 \%$ of Lawson criterion. A value of $E$ very much smaller than $r=0.01$ is probably not feastble because it results in large operating-power requirements.
For the conditions $\downarrow=10^{14} \mathrm{n} / \mathrm{cm}^{2}$. sec, $c=0.01$, and $n t=10^{12}$ the input power requirement $P$ is given by

$$
P=0.028 \mathrm{NAN}
$$

Under these conditions a pulsed plasma-focus test facillty with a test vcjume surface area $A=50 \mathrm{~cm}^{2}$ would requite operat ing power of 1.4 sit. For comparison, the area of a test factlity based on a mirror machine concept has been est imated to be $1.26 \times 10^{4} \mathrm{~cm}^{2}$, and thus, for $T=B \mathrm{kv}, \mathrm{nt}=10^{12}$ and $\varepsilon=0.01$ would require an input operating power of about $350 \mathrm{sW}$. A neutrontest facllity for these same conditions based on a I Inear theta pinch with $A=1900 \mathrm{~cm}^{2}$ would require a 53-M operating-power source. It can be seen that the power requirements for Sherwood-device-based test facilitles will be large because these lowdensity syatems necessarily occupy large volumes and thus have considerable surface area, of course, in principle, the power requirements could be reduced by increasing $\varepsilon$, but to achieve che pulsed-plasma-focus power requirement, a Sherwood-devicebased fac1lity would have to approach the break-nven condition of $E=1$. If some of the energy could be recovered through direc: conver:ion of high-energy lons and electrons 
then these power requirements would be reduced. However, unless nearfusion conditions are achieved, charge exchange between high-energy lons and background gas would reduce the effectiveness of direct conversion.

For completeness, we outline here the determination of $\varepsilon$. The fuston-energy production, $E_{F}$, for a 50-50 DT plasma is given by

$$
E_{E}=\frac{N(n \tau)}{4}\langle u v\rangle\left(f 2.8 \times 10^{-12}\right) \mathrm{J}
$$

or

$$
E_{F}=7 \times 10^{-29} \mathrm{fF}(\mathrm{T}) \mathrm{N}(\mathrm{nT}) \text {, }
$$

where

$$
\begin{aligned}
& 10^{-16} \mathrm{~F}(\mathrm{~T})=\langle\sigma \mathrm{\sigma}\rangle=\text { Maxwell } \\
& \tau=\text { confinement time } \\
& n=10 n \text { denstity } \\
& \mathrm{V}=\text { volume } \\
& \mathrm{N}=\text { total number }=\mathrm{nV} \\
& T=\text { temperature (kev). }
\end{aligned}
$$

Also, $f$ is the fraction of the $2.9 \mathrm{x}$ $10^{-12} \mathrm{~J} / \mathrm{DT}$ fusion considered avallable. For example, in arriving at break-even conditions $f=\frac{1}{5}$ because one assumes that only the 3.5-MeV a particle goes Into plasma heating, and the $14.1-\mathrm{MeV}$ neution energy is lost from the system. Fo- present purposes we w11 assume $f=1,1 . e, t h a t$ all of the $17.1 \mathrm{MeV}$ per fusion is the output energy.
The energy requised to heat the plasma to $T \mathrm{KV}, \mathrm{E}_{H}$, is given by $E_{H}=\frac{3}{2} 2 \mathrm{NT}(\mathrm{k}) \mathrm{J}=4.8 \times 10^{-16} \mathrm{NT} \mathrm{J}$, where $k=$ Boltzmann's constant. The energy lost to bremsstrahlıng, $E_{B}$, Is

$$
E_{B}=5.35 \times 10^{-31} \mathrm{NnTT}^{-5} \mathrm{~J} \text {. }
$$

We may also write

or

$$
E_{B}=R(T) E_{F},
$$

$$
R(T)=\frac{7.64 \times 10^{-3} T^{1}}{f F(T)} .
$$

Now if we require $E_{F}$ to be some fraction $F$ of the sum of $E_{H}$ and $E_{B}$, then we obtain

$$
\epsilon E_{H}=E_{E}(1-\varepsilon R(T)) \text {, }
$$

or

$$
\begin{aligned}
& \frac{E \mathrm{~T} \times 10^{13}}{\mathrm{~F}(\mathrm{~T})}=1.46(\mathrm{f}- \\
& \left.\frac{7.6 \mathrm{l} \times 10^{-3} \mathrm{FT} \mathrm{T}^{\frac{1}{2}}}{\mathrm{f}}\right)(\mathrm{n} \tau) .
\end{aligned}
$$

To obtafn the. condition for breakeven $(\varepsilon=1)$, we assume $T=10 \mathrm{kv}$ and $f=0.2$, and $F(10)=1.1$, and find $n \tau \approx 3 \times 10^{14}$ which is roughly Lawson's break-even cond :tion $\left(n \tau=10^{14}\right)$.

For the present purpose we are Interested in $\mathrm{f} \ll 1, \mathrm{f}=1$, and $0.1 \mathrm{kV}<\mathrm{T}<10 \mathrm{kv}$. In this range the term $E R(T)$ is negliglble, and consequently we may wrtte

$$
\varepsilon=\frac{1.46 \times 10^{-13}(\mathrm{n} \tau) \mathrm{F}(\mathrm{T})}{\mathrm{T}} \text {. }
$$

If we let $n \tau=g \times 2.0^{12}$, then the expression for $\varepsilon$ becomes

$$
\varepsilon=\frac{0.146 \mathrm{gF}(\mathrm{T})}{\mathrm{T}} \text {. }
$$


This is the equation used to determine the, values in Table 1. We can also see how, changes with $T$ for a fixed $n_{1}=10^{12}$, i.e. $\mathrm{g}=\mathrm{J}$. In this case

$$
\varepsilon=\frac{0.146 \mathrm{~F}}{\mathrm{~T}} \mathrm{~T} \text { (T) }
$$

Values of - from this equation for a range of values of $T$ are given in Table 2.

Table 1. Present experimental parameters

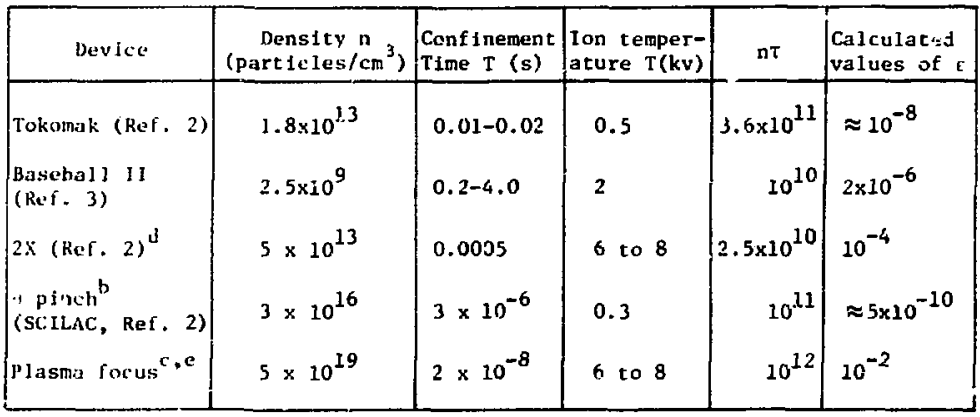

$a_{A n}$ increase in ion temperature by a factor 10 to $5 \mathrm{kv}$ would increase $\varepsilon$ to $1.4 \times 10^{-3}$

${ }^{b}$ An Increase in ton temperature by a factor 10 to $3 \mathrm{kv}$ would increase $f$ to $r=10^{-4}$.

cThe astual experimentally determined value is $\mathrm{E} \approx 3 \times 10^{-3}$.

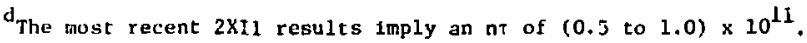

eIt is still a matter of contraversy as to whecher or not the neutrons from the high-density mode of the plasma focus are of hermonuclear origir. This debate persists due to a spread that exists in the neutron peak of at nost a - $*$ hundred kilovolts (the energy peaks at $0^{\circ}$ and $90^{\circ}$ ). From the $f$ ir.c of vit. of materials testing, such deviations from pure thermonuclear behavior are not significant. 
Table 2, $E$ vs $\mathrm{T}$ for $\mathrm{nt}=10^{12}$

\begin{tabular}{|c|c|c|}
\hline$T(k v)$ & $F(T)$ & $E$ \\
\hline 10 & 1.1 & $1.6 \times 10^{-2}$ \\
9 & 0.8 & $1.3 \times 10^{-2}$ \\
8 & 0.6 & $1.1 \times 10^{-2}$ \\
7 & 0.4 & $8.4 \times 10^{-3}$ \\
6 & 0.25 & $6.0 \times 10^{-3}$ \\
5 & 0.14 & $4.1 \times 10^{-3}$ \\
4 & $6.5 \times 10^{-2}$ & $2.4 \times 10^{-3}$ \\
3 & $2 \times 10^{-2}$ & $1.0 \times 10^{-3}$ \\
2 & $3 \times 10^{-3}$ & $2.2 \times 10^{-4}$ \\
1 & $7 \times 10^{-5}$ & $1.0 \times 10^{-5}$ \\
0.5 & $10^{-6}$ & $3.0 \times 10^{-7}$ \\
0.3 & $10^{-8}$ & $5.0 \times 10^{-9}$ \\
\hline
\end{tabular}

\section{Design Criteria for the SFG Repetitively Pulsed Material-Testing Device}

REQUIRED YIELD FOR RAPID PULSING

The dense-plasma focus produces the largest neutron yleld per unit plasma volume of any laboratory device now avaflable. For trradtation of materlals, however, it suffers from having a very slow repetition rate. Present day dense-plasma focus devices can be fired only about once every ten minutes, Obviously, for the devis to be useful for testing purposes a repetition rate of one or more times a second is needed. To accomplish this goa? the dense plasma focus must undergo extensive modifications. For example, the device 1tself must be cooled as well as the switches and capacitors. The cooling of this device presents stringent engineering problems. However, the designs described in this report appear to provide adequate cooling for the varfous components. 
Present plasma-focus devices have achleved $1.2 \times 10^{12}$ DD neutrons at $420 \mathrm{~kJ}$ stored energy. Figure 1
Is un empirical scaling of DD neutron yfeld $N$ vs stored energy $E$ for most of the plasma-focus machines which

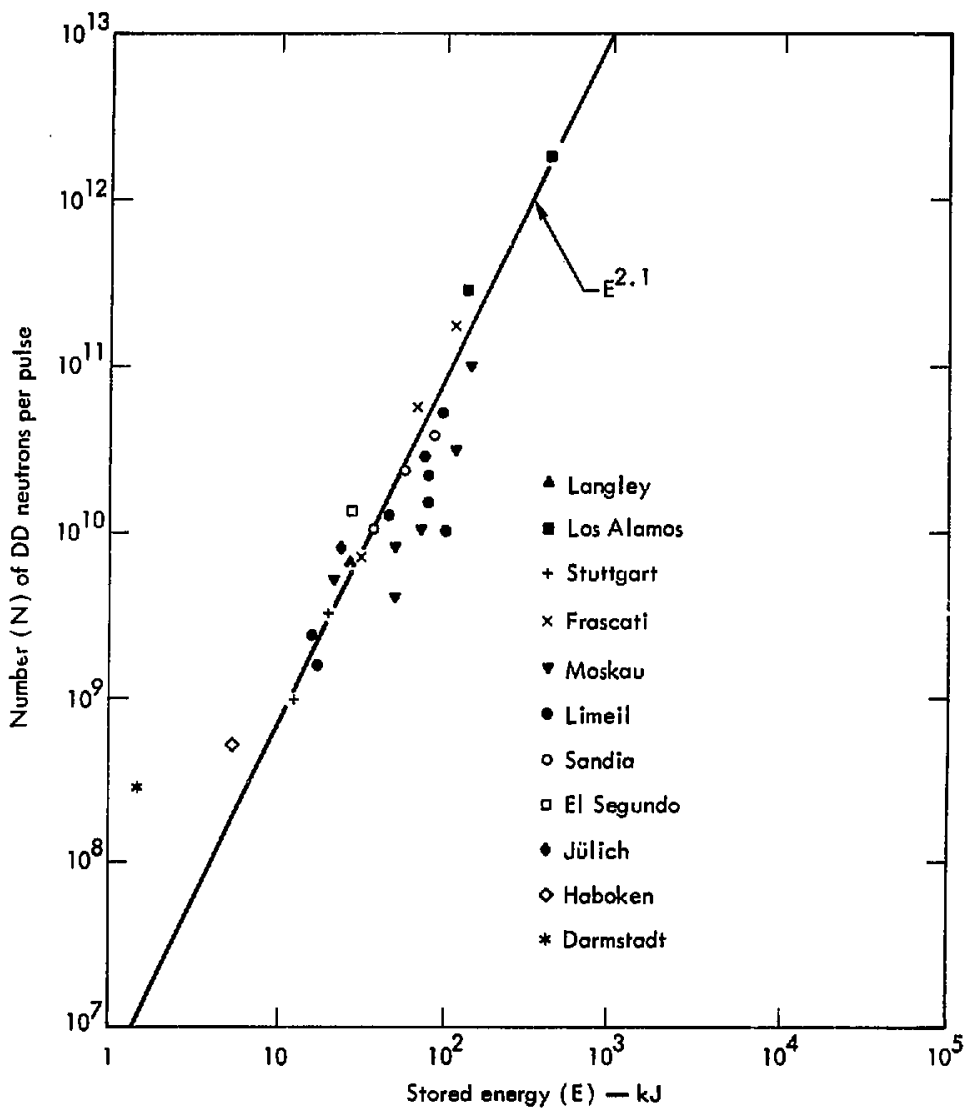

F18. 1. Neutron yield vo stored energy per pulse for various reactors. 
have been operated. ${ }^{4}$ These machines span a range in energy (E) of from $1 \mathrm{~kJ}$ to $420 \mathrm{~kJ}$ and a range in $\mathrm{V}$ $\left(E=\frac{1}{2} c V^{2}\right)$ of $10 \mathrm{kV}<\mathrm{V}<46 \mathrm{kV}$. The machines with the higher $E$ are designed to have, In general, somewhat larger $V$, but also larger capactance (C) and larger total Inductance (I). F1gure 1 shows an $E^{2.1} 1 \pm$ ne drawn through the points. One can see that the scatter of the points about the $E^{2.1}$ line is fairly large, espectally for the two machines with the lowest stored energy ( $E$ ) (Darmstadt and Hoboken). The machines shown in FIg. 1 have been designed according to the experience and taste of eleven different laboratories; no one parameter was kept constant in these varlous destgns. The predicted theoretical scaling according to Filippoy and Imshennik ${ }^{5}$ when $I$ is Increased as $\mathrm{C}$ and $\mathrm{E}$ are Increased is $\mathrm{N} \sim \mathrm{E}^{1.9}$. This predicted law agrees reasonably well with the $\mathrm{E}^{2.1}$ IIne which has been drawn on FIg. 1 when une considers trat the data of Fig. 1 came from eleren laboratorles where the values of $C$ and $V$ were chosen at w111.

However, the Bennett pinch relationship that $I^{2}$ × NkT and the lact that the magnetic energy avallable Is direct]y proportional to $\mathrm{I}^{2}$ suggests that the most important factor in directly determining $N$ is $I$, not $V$ or $E$, and therefore the scaling of $N$ vs I should be the most meaningful of all scaling relationships. Figure 2 shows $N$ vs $I$ for each of the machines for which we could obtain the approprlate value of peak current. It can be seen that the points lie falrly well on a $\mathrm{N} \propto \mathrm{I}^{5}$ line. The theoretical arguments of Filippov and Imshennik ${ }^{5}$ state that when a plasma-focus system remalns optimized and $\mathrm{L}$ and $\mathrm{C}$ remain constant, one should expect $N \propto E^{2.43}$ or $N \propto I^{4.9}$ $\propto v^{4+9}$. The agreement between the emplrical and theoretical values of the exponent here is fairly good. The two very small Darmstadt and Hoboken plasma-focus devices, however, lie considerably above the $I^{5}$ line as shown in the $N$ vs $E$ and N vs V plots by the Darmstadt group ${ }^{6}$ (Fig. 3). The line drawn through the data for this small machine Indicates $\mathrm{N} \propto \mathrm{V}^{8}$, which Implies $N \propto I^{8}$. Also note how both the Darmstadt machine and the small Hoboken machine (which are very similar; the Darmstadt machine uses an electrode structure fdentical to that of the Hoboken machine) lie considerably above the $I^{5}$ line in Fig. 2. The implication of these data Is that small machines with their more concentrated magnetic fields are basically supertor to the 


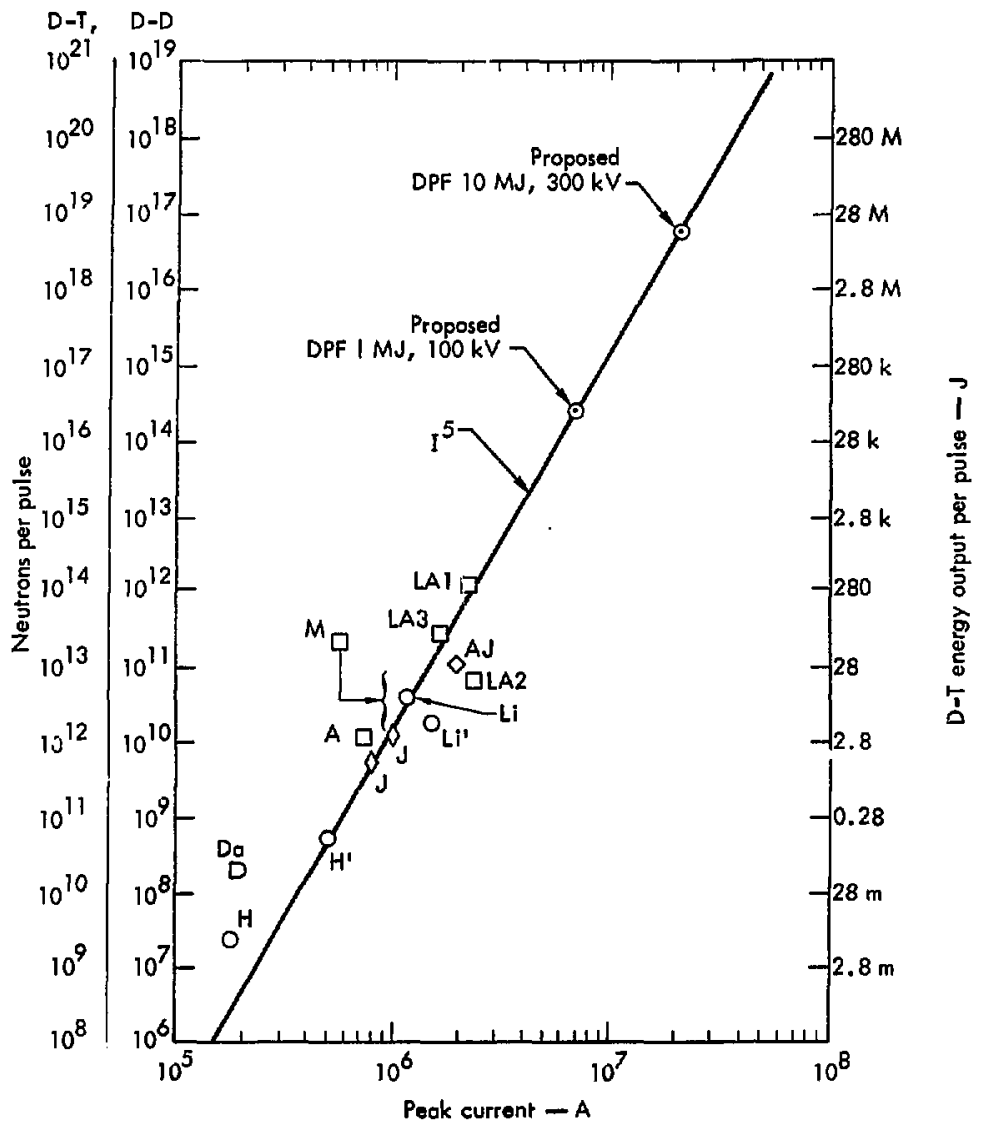

F1g. 2. Neutron yield vs peak curreat per pulse, and corresponding energy output. 


\section{Legend for Figure 2}

AJ Aerojet Nucleonics, $250 \mathrm{~kJ}, 20 \mathrm{kV}, 320 \mu \mathrm{F}$.

Da Darmstadt. $0.34-1.35 \mathrm{~kJ} ; 10-20 \mathrm{kV} ; \mathrm{C}=6.7 \mu \mathrm{F}_{\text {; inductance }}=24 \mathrm{nH}_{\text {; }}$ circuit frequency $=400 \mathrm{kHz}$; Mather type gun length $=10 \mathrm{~cm}$, diam $=5$ and $1.6 \mathrm{~cm}$; hollow center electrode. See Ref. 6 .

H Hoboken. Electrode structure is identical to that of Darmstadt group. 14 $18 \mathrm{kV} ; \mathrm{C}=6 \mu \mathrm{F}$; hollow center electrode. Now in operation at University of Buenos Aires. See Ref. 1.

$\mathrm{H}^{\prime}$ Hoboken. About $5 \mathrm{~kJ} ; 45 \mu \mathrm{F} ; 14 \mathrm{kV}$; time to current peak $1.8 \mu \mathrm{sec}$; Mather type gun; length $=14 \mathrm{~cm}$, diam $=10 \mathrm{~cm}$ and $3.4 \mathrm{~cm}$. Hollow center electrode.

$A^{E}$ Aerospace Corporation.

$\mathrm{J}$ Julich. $25 \mathrm{~kJ} ; 40 \mathrm{kV} ; \mathrm{C}=22.4 \mu \mathrm{F}$; center electrode $3 \mathrm{~cm}$ long; $6 \mathrm{~cm}$ diam; outer electrode $=11 \mathrm{~cm}$ diom.

Li Limeil. $96 \mathrm{~kJ}, 40 \mathrm{kV}$, induetance $=27 \mathrm{nH}$; $1 / 4$ cycle time $=2.5 \mu 5$.

$\mathrm{Li}^{\prime}$ Limeil. Plosma focus driven by explosive generator.

$\mathrm{LA}^{\dagger}$ Los Alamos. DPF-6; $420 \mathrm{~kJ}$.

$L^{2}$ Los Alamos. DPF-5; $120 \mathrm{~kJ}$.

$L A^{3}$ Los Alamos. DPF-6; $210 \mathrm{~kJ}$.

$M$ Moscow. $Y \rightarrow 10^{10}$ to $10^{11}$ DD neutrons; $I=1 \mathrm{MA}$.

larger machines, Although the data are still scanty, the message seems to be that the best design procedure Is to use very high $\mathrm{V}$ (several $100 \mathrm{kv}$ ), low $L$ (and $L$ ), and relatively small c to obtain high current. In doing so the designer can perhaps enjoy a scalling Iaw even better than $N \propto I^{5}$. Figures 4 and 5 show Los Alamos $N$ vs $V$ data for a $212 \mathrm{~kJ}$ machine, which shows a $N \propto V^{5}\left(\propto I^{5}\right)$ when the pressure was kept constant and
$N \propto E^{2}\left(\propto v^{4}\right)$ for DPF-5 and DPF-6 (Ref, 7) when the neutron yield is optimized by changing the pressure.

The SFG plasma focus proposed here is calculated to have a peak current of $7 \mathrm{MA}$ at $\mathrm{V}=100 \mathrm{kv}$ and $E=1 \mathrm{M} .3$. This machine w11l produce, according to the $I^{5}$ scaling, $3 \times 10^{16}$ DT neutrons per pulse and about $85 \mathrm{~kJ}$ In nuclear energy per pulse $(17 \mathrm{MeV}=$ $2.8 \times 10^{-12} \mathrm{~J}$ per DT reaction). If the voltage $V$ (and I) are ralsed by 


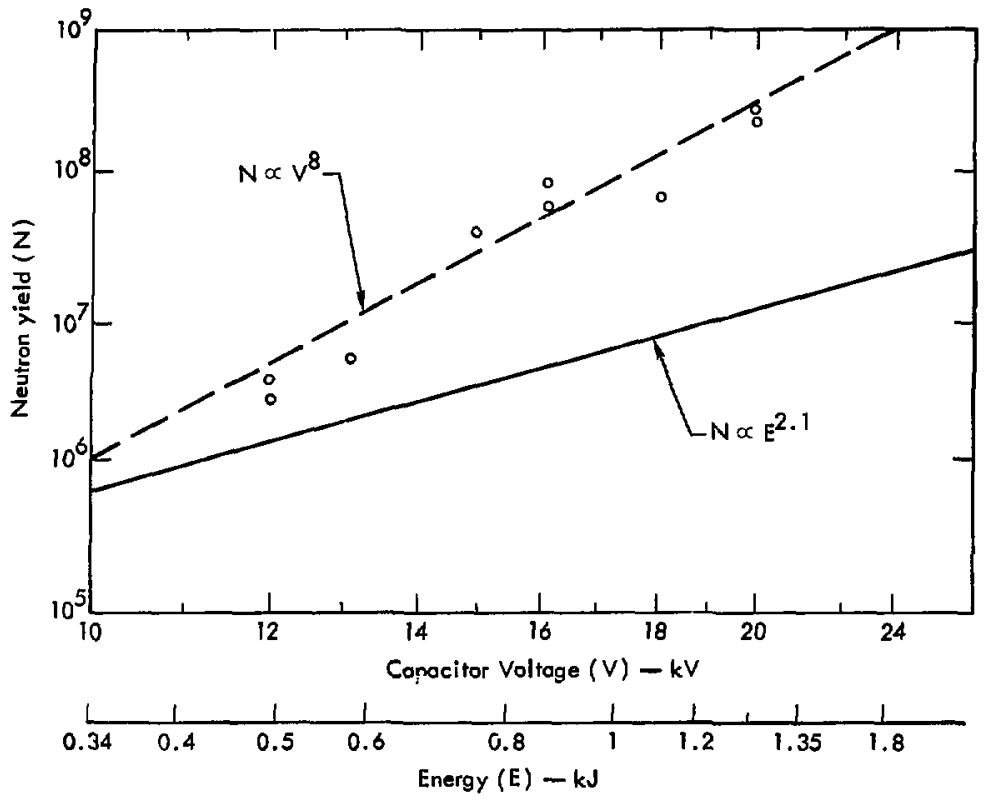

F18. 3. Neutron yields in relation to capacitor energy (E) and voltage (V) In Darmstadt machine.

a factor of 3 to $\mathrm{V}=300 \mathrm{kv}$

$(I=21 \mathrm{MA})$, the output is $6.5 \times 10^{16}$ DD neutrons per pulse $=6.5 \times 10^{18} \mathrm{DT}$ neutrons per pulse $=18 \mathrm{MJ}$ per pulse. The nuclear energy released per pulse will thus exceed $E$ (input energy) by a factor of 2 .

With the recycling of thout $50 \%$ of the energy (about $\frac{E}{2}$ left in the storage capacitance after each cycle) at 1 pps the average power consumed for the $100 \mathrm{kV}, I \mathrm{MJ}$ operational level will be $0.5 \mathrm{MW}$. The average neutron production w111 be $3 \times 10^{16}$ neutrons/ $s$, which is an average output power of $85 \mathrm{kw}$. Thus, on the average it operates at $17 \%$ of break-even. The capacitors and switches of the proposed bank must be designed conservatively enough to stand a repecition frequency of more than 1 pps. Therefore, if the user so desires, an 


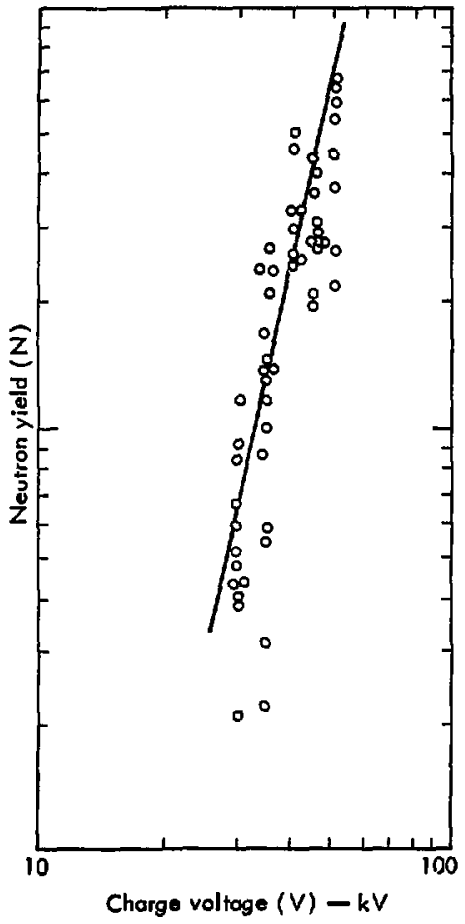

FI8. 4. Neutron yield vo charge voltage (Los Alamos DPF-6) (Ref. 7).

average yield of $3 \times 10^{16} \mathrm{DT}$ neutrons/ a can be attained. The capacitor is also designed to operate at $V=300 \mathrm{kV}$ at reduced repetition frequency. The user could then expect about $7 \times 10^{18}$ neutrons per pulse.

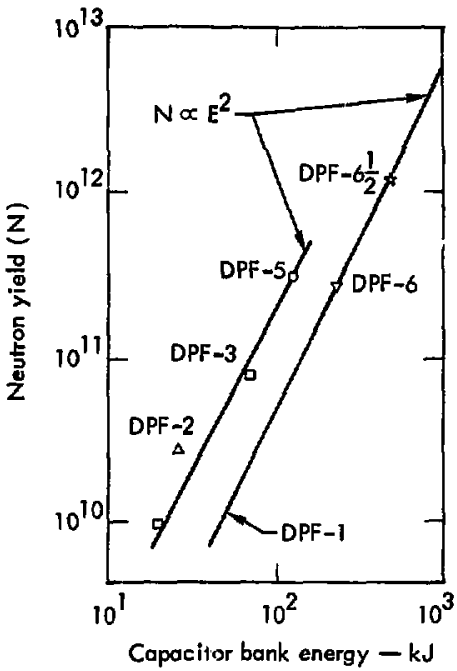

Fig. 5. Neutron yield vs capacitor bank energy (Los Alamos reactora).

The plasma focus will remain a point source. However, the Sigma Filippov (SFG) device proposed by LLL circumvents the we11-known window and access problems which have serlously curtalled the usefulness of the coaxial DPF as a testing device. The decision of the Euratom fusion group to use a Filippov-type, repetit Ivelypulsed plasma focus for material teating was very probably founded on similar considerations. 
The LLL SFG now being designed w111 be used for exploratory research work and component testing for the proposed rapid-pulse system. However, when such a testing device is built 1t must have we11-cooled electrical components, remote handling, control systems, a high-capacity power supply, a tritium handling facility and about six feet of radiation shlelding.

\section{ENERGY COUPLING TO PINCH}

As stated earlier, we would ? 1ke to maximize the current in the machine. Before we solve the circuit equations in detall we can make some general observations.

Let us assume that the plasma sheet runs down with a constant velocity and that the gun's inductance $\mathrm{L}_{\mathbf{g}}$ varies linearly with distance and thus with time. If a constant voltage sourne $V$ is applied across such a linearly changing inductance, we will obtain a constant current $I=V / \dot{L}$ where $\dot{L}=\mathrm{dL}_{\mathrm{g}} / \mathrm{dt}$. Thus maximizing $\mathrm{V}$ and minimizing $I$ will maximize the current. i can be mintwized by reducing the gun's Inductance and increasing the rundown time. The rundown time can be increased by Increasing the gas pressure. However, it has been shown experimentally that rundown time should be leas than 3 นร.
If the residual inductance $L_{B}$ is not zero as assumed earlier, then it will 1imit the current, since in a purely inductive clrcult we have $V_{\tau}=L_{B} I$. Thus, reducing $L_{B}$ and Increasing $V$ and $\tau$ will increase the current. With these considerations in mind, we designed a high $v$, low $L_{B}$, low $i$ system which will maximize the current while keeping the energy reasonably low. The following is a more detalled analysts of the circuit ucilizing a constant for the machine and showing computer plots of the results of more sophisticated geometries.

In the solution of the circuit In F1g. 6 the peak current $I_{m}$ for the plasma focus is not simply related to $v_{O}, C_{B}$ or $I_{B}$, where the subscrtpt $B$ refers to the bank. One must recognize that as the current sheath moves, there is an L term and thus the

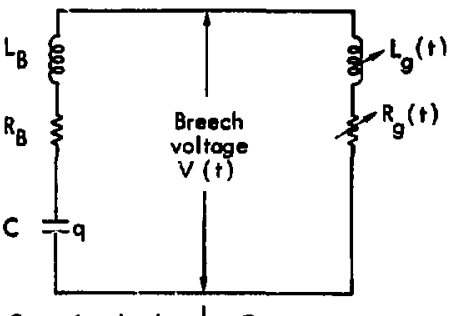

Capacitor bant: - - Coax gun

E1g. 6. Equivalent circuit of conxiel plasma gun. 
circuit of Fig. 6 is an attempt to take this fact into account. $L_{g}$ and $R_{8}$ refer to the inductance and resistance of the focus electrodes and plasma as seen from the breech, and $V(t)$ is the breech voltage. The appropriate differential equation is

$$
\frac{d^{2} Q}{d t^{2}}+\frac{(R+i)}{L} \frac{d Q}{d t}-Q / L C=0
$$

where $R=R_{B}$ and $R_{g}$ and $L=L_{B}+L_{g}$. Note that the $i$ term acts like a resistance as far as its effect on the circult current is concerned. Where $L$ does not change, the solution is osctilating (the underdamped case) for $R<2(L / C)^{1 / 2}$ and decays exponentially for $R>2(\mathrm{~L} / \mathrm{C})^{1 / 2}$ (the overdamped case). The breech voltage $V(t)$ Is given by

$$
\begin{aligned}
V(t)= & R_{g} I+\frac{d}{d t} L_{g} I= \\
& \left(R_{g}+\dot{i}\right) I+L_{g} \dot{I}
\end{aligned}
$$

and the power delivered at the input of plana focus electrodes 18

$$
\begin{aligned}
W(t) & =\operatorname{IV}(t)=R_{8} I^{2}+i_{8} I^{2}+L_{8} I \dot{I} \\
& =\underbrace{R_{8} I^{2}}_{\frac{8}{1}}+\underbrace{1 / 2 i_{g} I^{2}+}_{2} \\
& \frac{\frac{d}{d t}\left(1 / 2 L_{g} I^{2}\right)}{3} .
\end{aligned}
$$

Term 1 (above) is the rate of ohuic heating in the electrodee and the nonmoving platen; term 2 is the rate of doing machanfcal work on the plasma; term 3 is the rate of increase of magnetic fiold energy ingide the region between the two eleitrodes. Thus, $1 / 2 \dot{L}_{g}$ represents the equivalent resistance of the current sheet by virtue of its motion.

It can be shown that of the power delfvered at the breech, at most one half (1.e., $1 / 2 L I^{2}$ ) can be delivered to the plasma, and of that a half will be directed kinetic energy, the remaining being heat if the "snow plow" velocity is constant in a coaxial gun. With the assumption that the total resistance $\left(R_{B}+R_{g}\right)$ is constant and $\vec{L} \neq 0$ but $\vec{L}=0$, a solution can be obtained. This solution is applicable to the rundown phase of the operation of a coaxial plasma focus.

Shown in Fig. 7 are plots of current vs $t$ ine $\left(t / t_{B}\right)$ in terms of $I / I_{B}$ for several values of $u_{0}$. The following definitions apply:

$$
\begin{aligned}
& u_{0}=\frac{2\left(L_{B} / C\right)^{1 / 2}}{i} \\
& t_{b}=\frac{\pi}{2(L C)^{1 / 2}}
\end{aligned}
$$

(tine for the shorted-breech current to reach a maximum)

$$
I_{b}-v_{o}\left(c / L_{B}\right)^{1 / 2}
$$




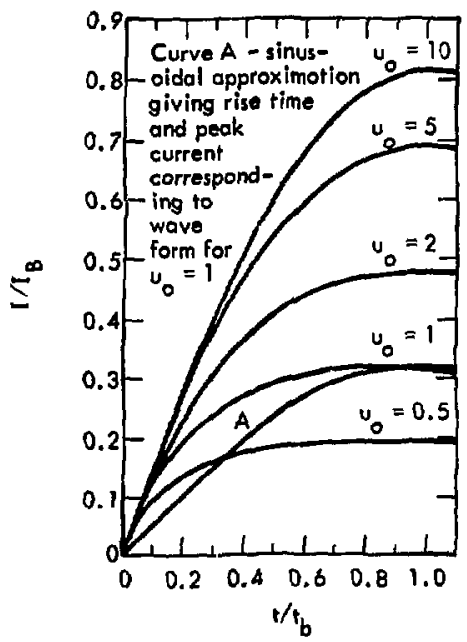

FIg. 7. Normalized current $I / I_{b}$ VB normalized $t$ ime $t / t_{b}$ for varlous values of $u_{0}=$ $2\left(L_{b} / C\right)^{1 / 2} / L$ for the case $R_{t}=0$.

(maximum current when breech is shorted and $R_{B}+R_{B}=0$ )

$v_{0}=$ Capacitar voltage at $t=0$

If we define $I_{m}$ as the value of $I$ at Its maximum, it can be seen that for large values of $u_{O}, I_{A} \cdot I_{B}$ and the time of $I$ - $I_{m}$ approaches $t_{B}$. Since $u_{0}$ is the racto of che characteriatic bank 1mpedance, $\left(L_{B / C}\right)^{1 / 2}$, to the of fact Ive resistance $1 / 2 \mathrm{~L}$ praduced by the velocicy of the plagar ateet, otrong damping effects are expected for $u_{0}<1$.

Curve A tn Fig. 7 shows the sinusoldal current waveform which glves the same peak current and rise time as the more exact expresston (for the case $u_{0}=1$ ). The curve IIlustrates that for values of $u_{0}$ near to and less than 1 the current, and the rate of work on the plasma, can be conslderably greater than that estimated on the basis of a sinusoidal approximation.

Solution of the circuit equation of the combined bank-gun system shows 'hat the attainable peak current $I_{\text {m }}$ is strongly affected by the relative impedance of the bank and gun. To a reasonable approximation,

$$
I_{m}=I_{B} F\left(u_{0}\right)
$$

where $F\left(u_{0}\right)$ is a funerlon which increases monotonically to 1.0 as $u_{0}$ Increases to values much above 1 . $F\left(u_{0}\right)$ is shown in Fig. 8. The condition $u_{0}=1$ is analogous to the condition for critical damping in an ordinary L-R-C circuit.

Although $I_{\text {in }} / I_{B}$ decreases with $u_{0}$, If is actunlly Increasing. This is geen by nocins that $u_{D} \propto L_{B}^{1 / 2}$ and $I_{B} \propto L / L_{B}^{1 / 2}$, so that

$$
I_{a}=I_{B} F\left(u_{Q}\right) \times F\left(L_{B}^{1 / 2}\right) / L_{B}^{1 / 2} \text {. }
$$

Since the numerator varies more slowly than the denominator, I le largee: 


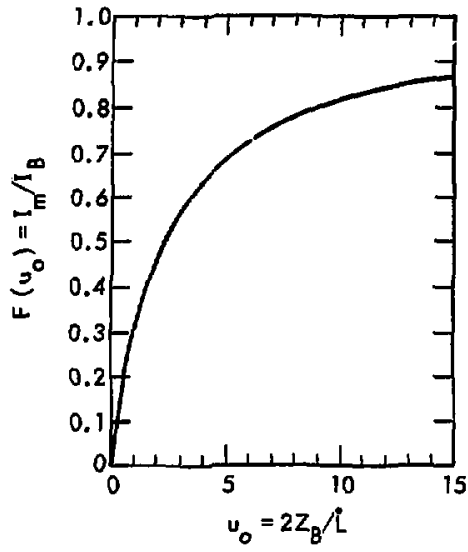

F18. 8. Maximuta gun current divided by maximum bank current vo bank Impedance divided by gun Impedance for a coaxial plasma gun.

when $\mathrm{L}_{\mathrm{B}}{ }^{1 / 2}$, and thus $u_{0}$, is snallest. $A$ rough estimate (good to about +25\%) gives

$$
F\left(u_{0}<1\right) \approx 0.4 u_{0} \text {. }
$$

Thus, in this range, maximum current Ig

$$
I_{\pi}\left(u_{0}<1\right) \approx 0.8 v_{0} / \dot{L} \text {. }
$$

This reault agrees in general with the result for the conetantvoltage case. The foregoing dthisusion asouma a constant valocity rundoan in a coaxial geometry, Making the aame constant-velocicy assuption in the
SFG yields $\dot{L} \propto \frac{\mathrm{v}}{\mathrm{r}}$ where $\mathrm{v}$ is the sheath velocity and $r$ is the Instantaneous redius of the sheath. A posstble further modification is to monotonlcally decrease the electrade spacing in the SFG thus obtaining an even gmaller $\dot{L}$. Figure 9 shows these three bastc geometries and their inductance-vs-time curves.

Figure 10 shows the results of a computer calculation of the proposed capacitor-bank source for various Inductance vs time curves of the load. It is important to realize that the final collapse in the coaxial system really corresponds to the later stage of the Filippov pinch. Thus, the proper comparison of current should be where the SFG radtus equals the Inside coaxial-gun radius. The corresponding values $\left(I_{m}\right)$ are $6 \mathrm{MA}$ for the coarial gun and $7.8 \mathrm{MA}$ for the Filippov geometry. The continued current decrease beyond this point does not represent a decrease in stored magnetic energy until point "B" in Fig. 10. After point "B" In time, a radial collapse of the current sheath occurs causing a great increase in energy density. However, the rate of work done on the plasma exceeds the rate of energy input from the bank, and the total energy In t.ue gun decreases. During the rundown and the early part of the pinch, flux Is conserved. Anowalous restitance 


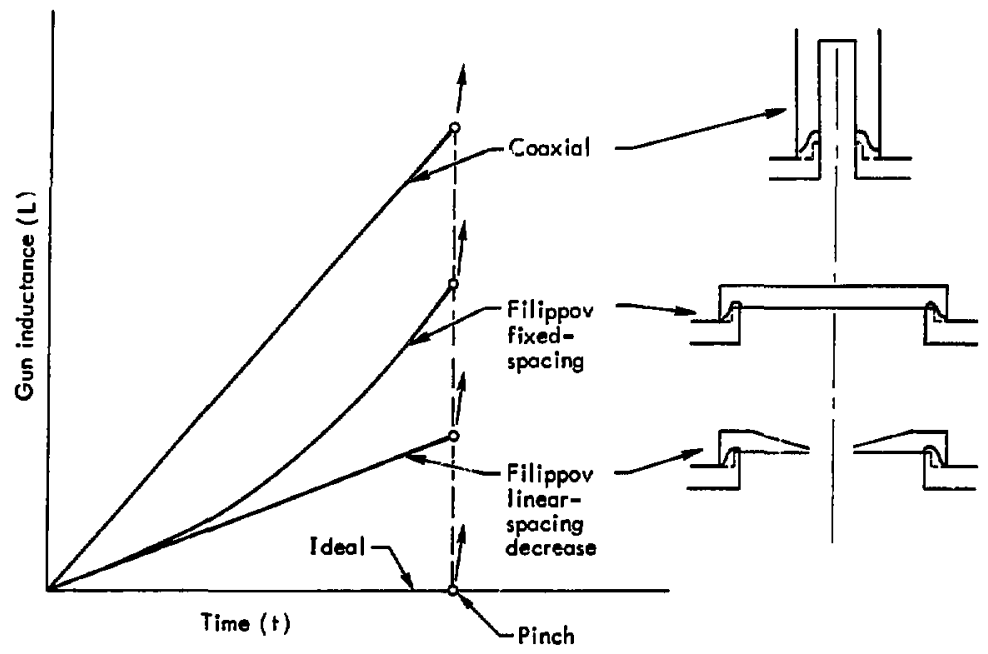

Fig. 9. Inductance vs time for various geometries.

(flux destruction) occurs later in the pinch.

\section{SIGMA FILIPPOV GEOMETRY}

The foregoing Jiacussion tllustrates some basic characteristics of the DPF which can be exploited in the SFG we are proposing for use in materfal and component test Ing. The proposed SFG electrode atructure 18 shown In Fig, 11 and $1 \mathrm{~g}$ discussed in detall in the paragraphs that follow.

Inductance T1me-Depeudency

$$
\text { In a coaxtal gun the increase }
$$
In Indurtance in the rundown phase is linear with distance. Therefore, If the plasma sheet progresses at constant speed there is a constant rate of Inductance Increase with time. In the filippov there is a radial rundown. Since the inductance vartes with the $\log$ of the radius, i will vary with $\mathbf{r}^{-1}$. For a constantvelocity rundown, this behavior is shown in Fig. 9. Initially, the SFG inductance vertes slowly, and thus $i$ is small at the time the voltage on the capacitor is largest, thus allowing for a rap1d buildup of current. Eventually, close to pinching, i becomes very large but 
Coaxial gun

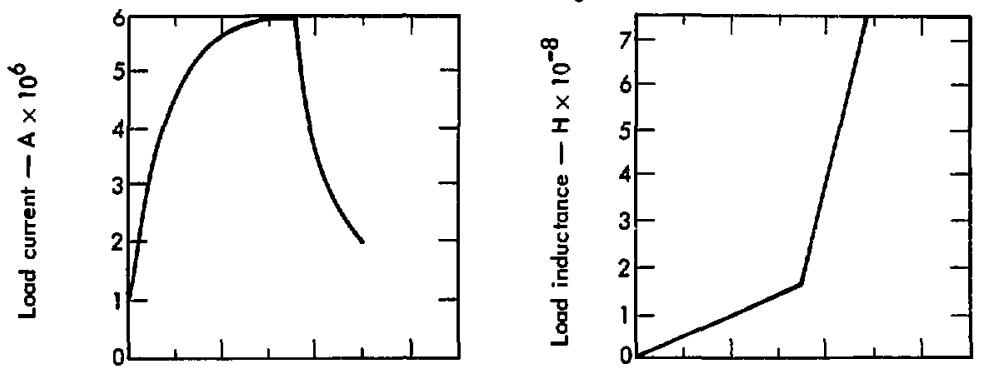

Fixed-spocing filippov

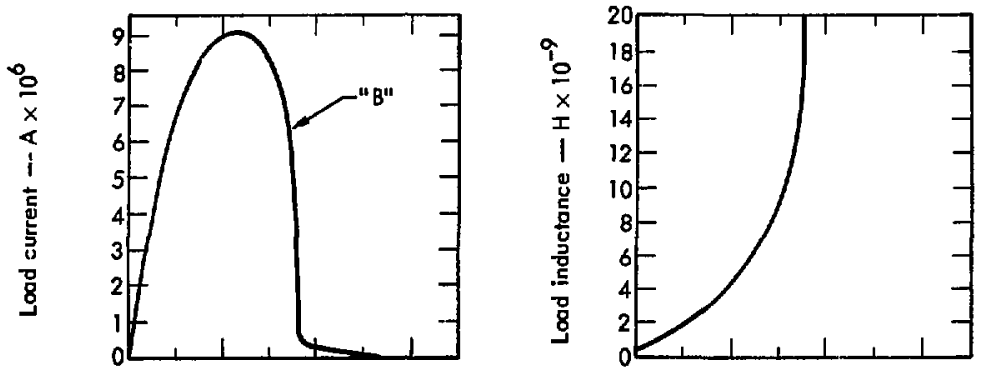

Linear-decrease Filippov
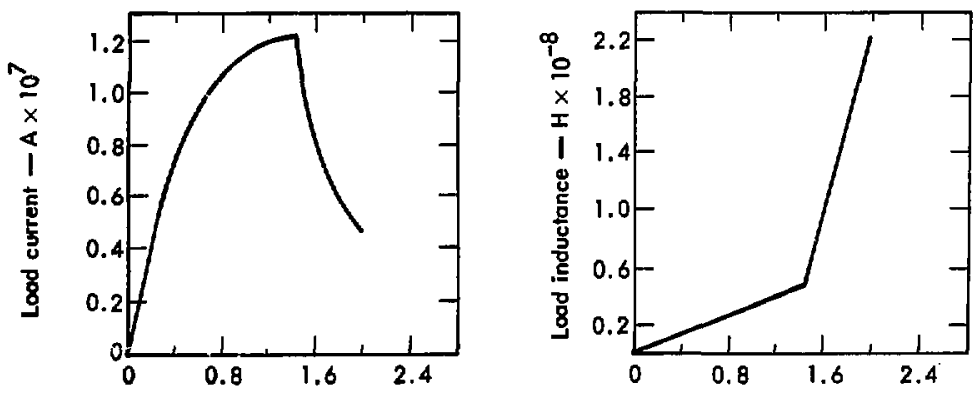

Time - $\mu 5$

F18. 10. Calculated load current for varfous inductance vs time curves of the load. 


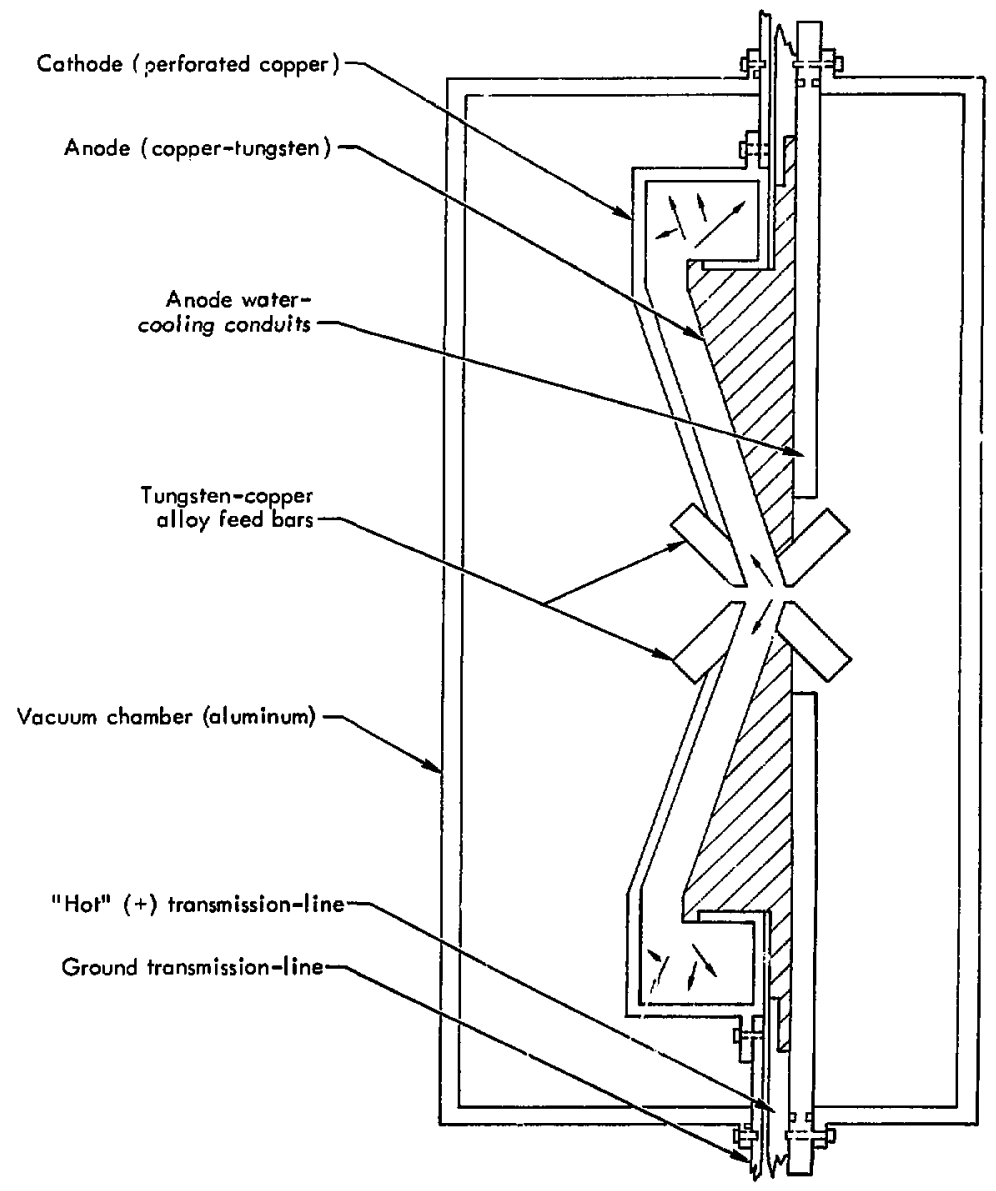

F1g. 11. Sigma-Filippov-geometry (SFG) electrode atructure showing tungsten-copper alloy feed bars at locations of high current density. 
this happens after the gun has recelved most of its energy from the capacitor and therefore doesn't affect the energy transport to the gun. A F111ppov geometry with monotonically decreasing spacing is also shown in Fig. 9. This geometry affords the highest current buildup.

\section{Low Initial Current Density}

A I MJ coaxial gun would have a center (anode) electrode about 9 to 10 Inchea in diameter, whereas a Filippov device of the same energy would be more than three times as large. Thus, the breech-current density of the Filippov gun would be about 30 percent of the coaxial gun for the same energy. This reduced current density will decrease problems of insulator erosion and restrike.

Large Target Area and Plasma-Focus Accessibility

One of the thajor limitations in utilizing the plasma focus as either a neutron or $x$-ray testing device is the destructive character of the effluent from the focus and the difficulty of placing samples near the focus. This has become known as the "window" problem. The SFG has greatly reduced these limitations. Reference to Fig. 11 shows how samples can be placed on either slde of the focus in the SFG. To avoid effluent damage, metal folls could be transported across the electrode aperture to isolate the samples from unwanted radiation. We have conducted experiments with rolls of deuterated polyethylene $\left(\mathrm{CD}_{2}\right)$ foll where a new surface is exposed on each shot. There are no basic technological problems in producing folls with equal mixtures of $\mathrm{CD}_{2}$ ard $\mathrm{Cr}_{2}$. Heavy metal folls would be useful in those cases where enhanced $x$-rays are desired.

Wth a one-meter-diameter center electrode, samples of varlous sizes can easily be positioned to within a few centimeters of the focus in a region outside of the discharge chamber and, therefore, uncontaminated by tritium. Or, for large-area irradiations of test reactor wall materlals in a realistlc plasma environment, the senter electrode can be made of the test material and recelve the full plasma and $x$-ray bombardment in addition to the neutron irradiation. At a neutron yield of $3 \times 10^{16}$ per shot, areas of a few square centimeters can be irradiated to $6 \times 10^{14}$ neutrons $/ \mathrm{cm}^{2}$ per shot. Th1s presupposes a distance of $2 \mathrm{~cm}$ from a point neutron source. At 1 pps, the sverage neutron flux would then be $6 \times 10^{14}$ neutrons $/ \mathrm{cm}^{2}, 8$. If the 
tests require $10^{14}$ neutrons $/ \mathrm{cm}^{2} . \mathrm{s}$, the test sample can be placed $5 \mathrm{~cm}$ from the source.

Cooling

In a rapidly pulsed plasma-focus device, essentially one-half of the megajoule of stored energy released once per second ends up as heat somewhere In the system. The greatest fraction of this heat is depusited In the electrodes and the walls, and must be dissipated to keep system temperatures within allowable $11 \mathrm{mits}$. For a one-meter dlameter conventional Fllippov geometry, as the current sheath collapses during the bank quarter-cycle-time of approximately 3 us, the energy is distributed in a fatrly uniform fashton over the surface of the plates forming the electrodes. An exception to this is In the region about $5 \mathrm{~cm}$ in radius at the center where the current density becomes very high. If the entire megajoule were deposited in one copper disc a meter in diameter and $1 \mathrm{~cm}$ thick, the temperature would rise about I degree $C$. Thus, for continuous operation, coolant flow is necessary.

With water as the coolant and allowing a $10^{\circ} \mathrm{C}$ temperature rise, the required flow rate is about 400 gallons per minute. This could be accomplished by havisg cooling water flow inside the anode and cathode electrodes (F1g. 12), The heated water would then be cooled in a heat exchanger and rectrculated. The thickness of the cooling water layer would not be sufficient to appreclably alter the neutron spectrum through thermalization. Furthermore, small test samples can be placed very near the plasma focus without any water Intervening between the sample and the neutron source.

The center regions of the electrodes, where the radius is less than about $5 \mathrm{~cm}$, are made up of radial tungsten bars to reduce erosion. These bars (see FIgs, 11 and 12) can be repositioned as they erode. The tungsten bars which form a portion of the electrodes are designed to have a 3-cm-radius hole in each electrode, reducing the current densities at the electrode surface at the time of maximum pinching. Indeed, for center electrodes without holes, in the Mather coaxial geometry, the "pinch" Is observed to $\mathrm{dIg}$ a hole in the end of the center electrode in only a few shots. At high current levels the rims of the holes will be subje:t to erosion and with repetitive pulsing the energy dissjpated per $\mathrm{cm}^{2}$ in this region will be high (about $1 \mathrm{~kW} / \mathrm{cm}^{2}$ ). The electrode structures should be constructed in a manner which will permit the bu's .f the "snowplowed" plasma, during the rundown, to leak 


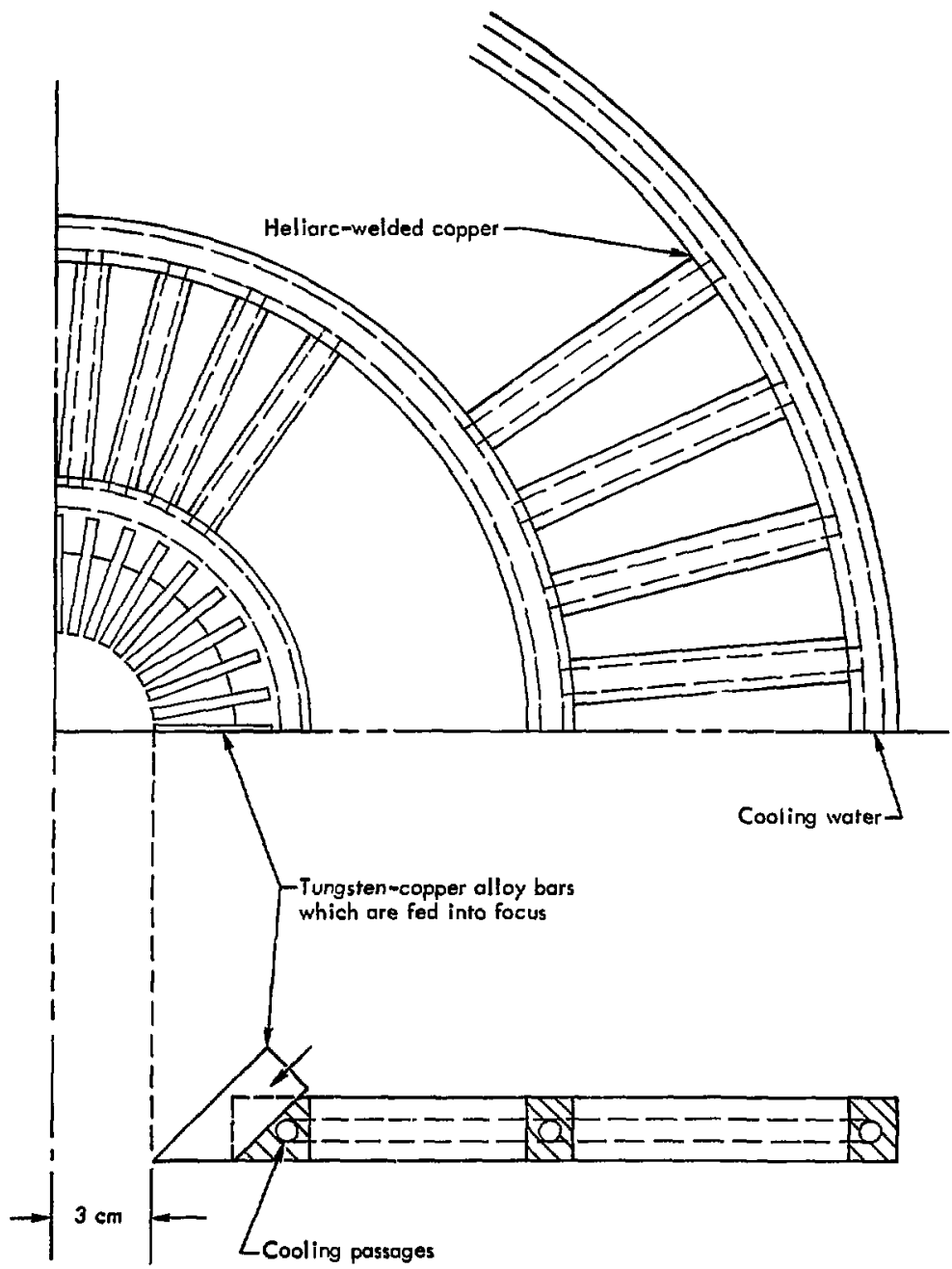

F1:. 12. Construction of outer electrode with slots to permit escape of driven plasma during rundown. Construction shows water cooling labyrinths. 
out through perforations or slots in the cathode electrode (see Fig. 12).

\section{Shielding}

The electrodes in a dense-plasma focus are highly immune to neutron radiation since they are made from the best materials avallable, such as tungsten and tungsten alloy. The insulator at the breech however will suffer from radiation damage if not properly shielded. The $\Sigma$ shape of the electrode was designed to allow rucking the 1ssulator behind massive shielding, thus protecting it from radiation damage, as shown in Fig. 11 .

It thus appears reasonable that a plasma-focus testing system based on the SFG concept could be developed to produce $>10^{16}$ neutrons per second over long periods of time. A factor of major importance is that no highly uncertain extrapolation of ylelds or basic physics is required to reach the goals indicated. The problems, while very tough, are primarily technologica1 in nature. It is obvious, however, that a vigorous research program on our present SFG device could well lead to significant improvement in the performance of an actual testing device.

\section{STEPPED INDUCTOR}

In a high-voltage DPF, voltagepulse shaping will probably be necessary. Pulse shaping will permit application of bank voltage to the load In a gradual manner. The formation of the current sheath then takes place under low-voltage stress conditions. Only after the current sheath lift-off has occurred is the full voltage applied to the load.

To provide pulse shaping, a nonlinear impedance is put in series with the load. The impedance is Initlally high relative to the load and gradually decreases (1n approx. $0.2 \mathrm{\mu s)}$ to a sma 11 value relative to the load. A saturable ferromagnetic material is ideally suited to this requirement. A core made of $1-\mathrm{m} 11$ thick 50-50 nickel-1ron tape (or Hypersi1), $2 \mathrm{~cm}$ high, with an inner radius of $1 \mathrm{~m}$ and outer radius of $1.67 \mathrm{~m}$ (properly sectloned and gapped) w1ll adequately satisfy this requirement. 


\section{Energy Supply and Capacitor Bank}

INTRODUCTION

There are several special requirements that must be met by a capacitorbank used in a pulsed system. The bank must deliver in a few microseconds at least $1 \mathrm{NJ}$ of energy at $100 \mathrm{kV}$ once per second for upwards of $10^{7}$ shots. A continuously operated $1 \mathrm{MJ} .100 \mathrm{kV}$, 200 uf, low-inductance (about $5 \mathrm{nh}$ ) capacitor bank introduces considerations that are usually neglected in the design of a single-shot capacitor bank such as is used in all of the currently operated plasma-focus maclines. Continuous operation at 1 pps requires that component 1ifetimes be increased by several orders of magnitude. The problem of heat dissipation by the components becomes of great Importance and must be an integral part of the design. The low inductance requirement of the design will bo difficult to achleve with current techniques, as the volume of the bank will be greater.

In order to see how all of these considerations are interrelated let us cunsider first the high voltage requivement. The maximum permitted electric field between the foils of a capacitor 1s approximately $160 \mathrm{mV} / \mathrm{m}$ $(-4 \mathrm{kV} / \mathrm{mI} 1)$. In the staggered foil construction normally used, at this electrical stress coronn from the sliarp edges of the coil carbonizes a path bel teen the foll edges. See Fig. 13. This corona limite the lifethe of the capacitor to about 1000 shots.

With cont inuous operation at 1 pps, millions of shots will be required. Hence, the capacitor design must use an electric fleld lou enough to el lalnate the cornna, namely $40 \mathrm{mN} / \mathrm{s}(-1 \mathrm{kV} / \mathrm{mil})$.

Since the electrostatic energy density is proportional to thu squine of the electric fleld, the reduct ion of the electic-field stress in the dielectric from 4kv/mil to $1 \mathrm{kV} / \mathrm{mi}$ l will requite a 16-fold Increase of the volume of the capncitor difelectric In order to store the same amount of energy.

A small fraction of the energy stored in a capacitor is dissipated as heat in the conducting folls because of the high currents uhich flow when the capacitor is discharged. With continuous operation at 1 pps, conventional capacitors would soon succumb to thermal runaway and be destroyed. Obviously the surface-to-volume ratio of the capacitor un 1 ts must be greatly increased. The question now confronts the designer: Can such a large high- 


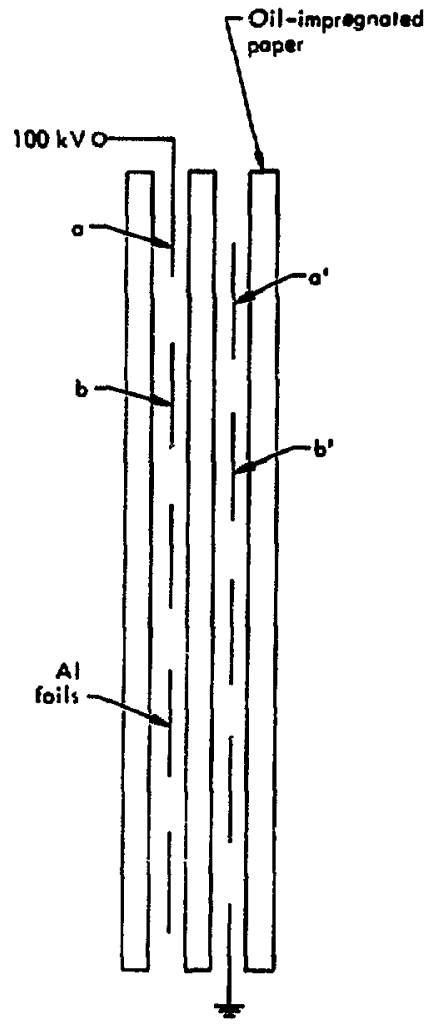

F1R. 13. Scaesersd-foll-conetruction capac1 tor.

volcage capactior with large surfaceco-volume rat to be bullt and atil satisfy the low Inductance requirementa? The angwer is yes. But in order to achleve chis goal the design musc we 11 the new and improved cechnlques which nre not customarliy awa lable in convent lonal capacitor deslign.

THE CAPACITOR BASK

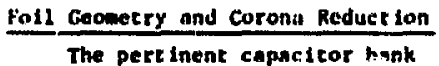
dusign parameter goals are E - $1 \mathrm{H}$, $v$ - $200 \mathrm{kV}$. average perear - I iw at I pps, capacitance - 200 ff wizh a serleg Inductance of less than $5 \mathrm{nill}$. The staegered-foll construction of a convent lonel, high-energy, highvolrago capacicor is show in Fig. 13. In this cigure, oll-impregnated paper separaces two nets of folls mounted in a scasgered fashion. Ef fectively. the folls reprowent a group of capacitors connocted in seriog. In Figure 13. If the voltage between Iolla and $a^{*} 18 v$, then the voltage between a and b is $2 \mathrm{~V}$. Purcliermore. che voltage becween $a$ and $b$ is not chrough the oll-impregnated paper but is alons the surface of this paper. This typo of "crecp seress" aiong the gurface of the paper encourages the corona which will carbonize the surface unt 11 breakdown occurs. A breakdown or short between folls a and $b$ incrcases clie stress in the remaining sections of the capacteor. and fallure of the entire capacitor 
will soon follow. A creep-stress figure of $40 \mathrm{~V} / \mathrm{mll}$ Includes a safety factor comensurate with a throughthe-paper stress of $1 \mathrm{kV} / \mathrm{m} 1 \mathrm{l}$.

In the design which we propose, a variation of the staggered construction will be used whtch does not fuxtapose the edges of adjacent folls. In the proposed design (Fig. 14) each foil edge is separated by a layer of paper frow all other foll edges. This procedure allows a smaller off tet of one foll with respect to its nafghbor, provides a greater volute efficiency for a given length, and has supertur edge protection.

The assembly of such a capacitor is accompltshed by winding a single strip of paper sheet on a mandrel and Inserting the single turns of foil sectlons, each one with an axial nffset with respect to its predecessor.

Such capacitors have been constructed on cylindrical mandrels and tested at our laboratory. In the proposed case we will use an elongated (oval) cross section mandrel as shown in Fig. 15.

Capacicive-Section Destgn and Cooling Cons iderat Ions

The previous section discussed the type of construction necessary to deal will the corone problem at the edges of the foils. In this section we examine actual figurea and arrive

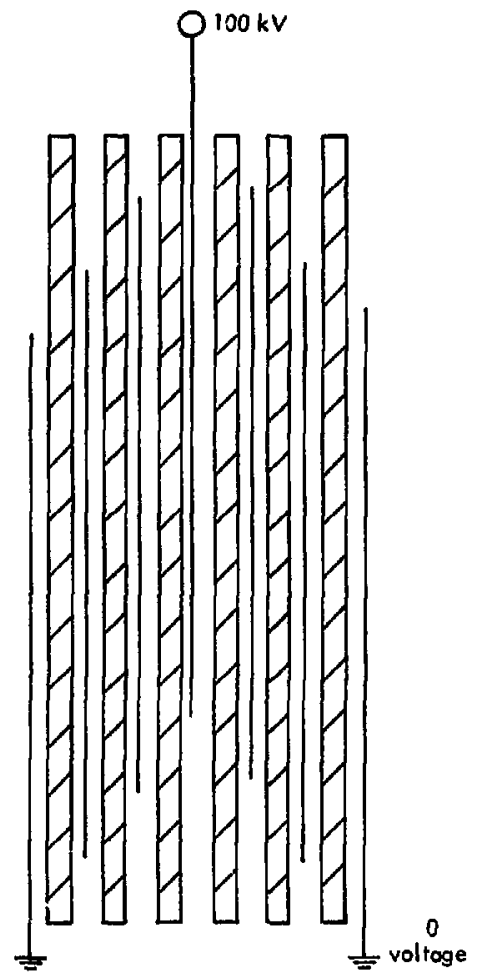

F18. 14. Proposed high voltage capacitor with axially offset folls.

at dimensional criteria for the construction of the basic capacitor sections, taking into account the necessities of adequate cooling. 


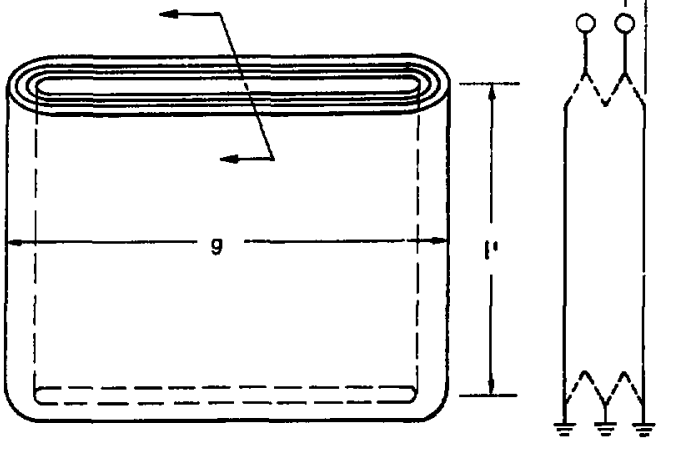

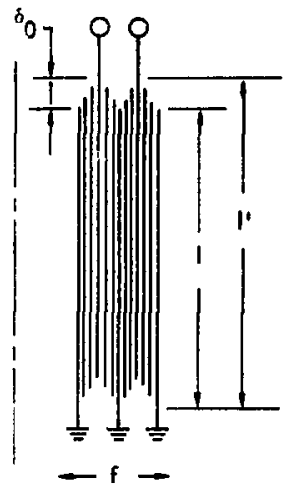

Fig. 15, High-valtage capacitor with vane cross section.

For ease of construction and malntenance, we are interested in building basic capacitor sections which store between $0.5 \%$ and $1 \%$ of the total energy. The geometry of such a section, which is shown in Fig. 15, is a plane rectangle where the folls are stacked in the plane. We w11l call this rectangle a "vane", whose cross section 18 shown at the right In Fig. 15.

The dimensions of the vane must be determined on the basis of voltageholding capability and cooling requirements. The vane is constructed of a number of subsections. Each section of width "a" holds $100 \mathrm{kV}$ and 18 made of in folls, each cunsisting of aluminum of thickness $s_{\alpha f}$ and o11Impregnated paper of thickness $\delta_{p}$, so that

$$
a=m\left(\delta_{x i}+\delta_{p}\right)
$$

At : $k V$ per mIl, and the choices of $\delta_{\alpha \ell}=1 \mathrm{mil}$ and $\delta_{p}=5 \mathrm{mil}$, then m $=20$ and "a" = $120 \mathrm{mil}$ (1.e., $3 \mathrm{~mm}$ ). The volume efficiency $(n)$ is given by the ratio of the energy-storage volume over the total volume of the section. To hold the total voltage from the tip of the bottom foll to the top plate, an offset of $\delta_{0}$ ia proposed. This value is determined conservatively to be $\delta_{0}=100 \mathrm{kV} / 25 \mathrm{~V} /$ $m 11$ - 4.1n $\approx 10 \mathrm{~cm}$. The length " $l$ " 18 assumed to be $1 \mathrm{~m}$. Thus, 


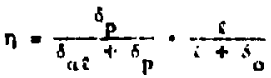

$$
\begin{aligned}
& -\frac{5}{1+5} \cdot \frac{1}{1+0.1}=0.75
\end{aligned}
$$

The firat term nccouncs for the thlckness of the nluminum and che second term accounty for the volumeof fset losacs. This volume effictency does not include the mandrel volume or the volume surround ing the vanes. The volume is $2 q^{\prime} \mathrm{Fg}$. If an additional 157 width is used for coolfrib then the added volume is $2 R^{\prime} 0,15 f \mathrm{~g}$ and volume effictency goes to $\frac{1}{1+0.15} n=0.65$.
We now comslater the minimum exposed surfice aren per sect Ion necessary for adequate cool lug. Figure 16 shows experimentally-derived data which plat the temperiture rige of the surfuce of an $n$ ir-cooled oilImpregnated paper capueltor vs load restatance and wattage/sijgare Inch of capacitor aurface area. A brief discussion of the origin of the cemperature-rise dependence given in these curves is found in Appendix B.

To determine $R_{d \text { lscharge }}$ for our

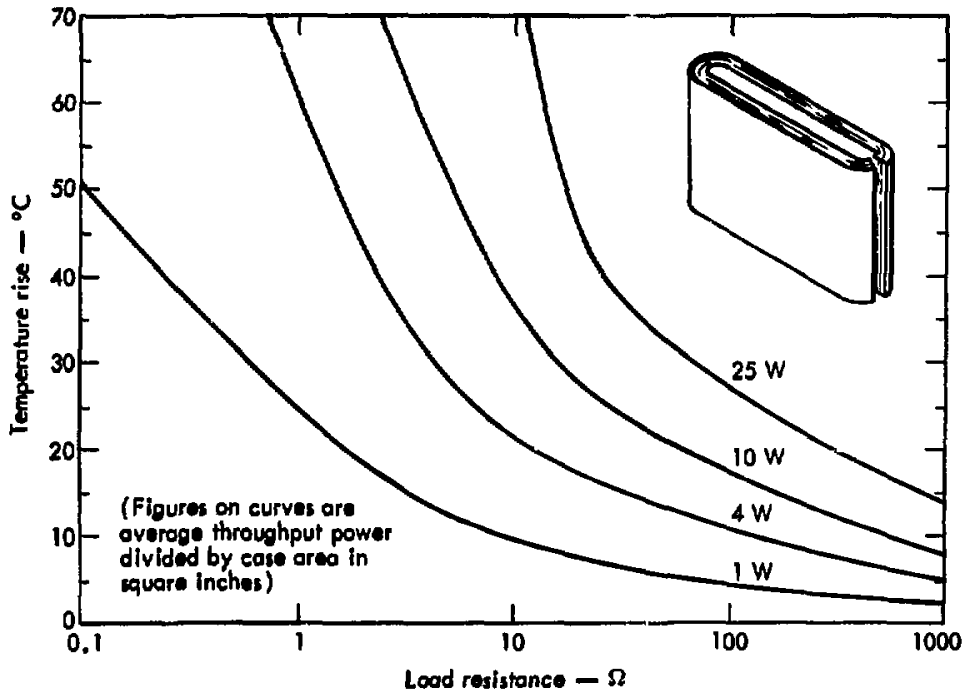

F18. 16. Tenperature rise vs external lond resistance. 
systems we call sily that each vane cieries a surent of 1 total $/ \%$, where z. is the number of vanes. lionce, Risillarge per vane is

$$
\begin{aligned}
K_{\text {discinatge }} & =\frac{12}{1 \text { Lotal }} \\
& \approx \frac{10^{5} \div \frac{100}{10 \times 10^{6}}=1}{10 \times 1}
\end{aligned}
$$

where

$$
V=\text { cotal vol tage }-100 \mathrm{kV} \text {. }
$$

With selection of a temperature rise of $25^{\prime \prime} \mathrm{C}$ as an appropriate figure and $R_{\text {discharge }} 1 \%$, the corresponding curve in FIg. 16 Indicates a power of 1 watc $/ \mathrm{in}^{2}$. This figure of

1 watt $/ 1 n^{2}$ is a very conservative and safe cholce because it is for an alrcooled capacitor can and we are using this figure for an oll-cooled capaclator vane. We will use 1 watt $/ 1 \mathrm{n}^{2}$ - $(40)^{2}$ watt $/ m^{2}$ as the ef fectIve power-to-area ratio, P/A, of our capact tor vane. Thus,

$$
A=\frac{p}{(40)^{2}} m^{2}
$$

A vane $1 \mathrm{~s}$ wound on a permanent hollow mandrel where cooling $1 \mathrm{~s}$ provided on both the outside and the 1.sside of the vane. The total volume per section In our geometry, excluding the mandrel and external space, Is given by

$$
V=2 Q^{\circ} g f=\frac{V}{n},
$$

whore $V$ is the energy-storage volume and i: Is the volutue effletency.

The net volume y per vane equals the unergy per vane divided by the energy density. W is the total energy storad in the bank and $z$ is the number of vanes, so that

$$
v=\frac{W}{2} \cdot \frac{1}{\frac{1}{2}+E^{2}} .
$$

The equat ion,

$$
v^{\prime}=2 i \cdot g f=\frac{W}{2} \cdot \frac{1}{\frac{1}{2} \in E^{2}} \cdot \frac{1}{n}
$$

relates the dimensions of the vanea to parameters which determine the volume, without yet having considered the space occupied by the hollow mandrel and the spacing between sections. To calculate the thickness of the vane "f" we determine the surface-to-volume rat10. The surface area avallable for cooling each vane 1s, from Fig. 15, equal to $4 f^{\circ} 8$. The surface-to-volume rat to for our geometry then is:

$$
\frac{A}{V^{\prime}}=\frac{4 l g}{2 l^{2} g f}=\frac{2}{f} \text { or } \frac{P}{(40)^{2}} / \frac{W}{\frac{1}{2} c E^{2} n} .
$$

Solving for $f$ we obtain:

$$
f=\frac{4 W \cdot(40)^{2}}{E E^{2} n P}
$$

Substituting Wg $=$ P, where 8 is the number of shots per second, the vanc width becomes: 


$$
f=\frac{4 x(40)^{2}}{c E^{2} n 8}
$$

For example, if we cake $s=1$, $E=40 \times 10^{6} \frac{y}{n}, n=0.65$,

$E=5 \times \frac{10^{-9}}{36 \pi}$ (for castor o11), then,

$$
\begin{aligned}
f & =\frac{4 \times(40)^{2} \times 36}{5 \times 10^{-9}\left(40 \times 10^{6}\right)^{2} 0.65} \\
& =0.14 \mathrm{~m}=1 \mathrm{~cm} .
\end{aligned}
$$

This is a congervat ive upper $11 \mathrm{mit}$, from the point of view of cooling, to the thickness of the "roll" which forms the vane (see FIg. 15).

For a $1 \mathrm{MJ}$ capacitor the net volune of dielectic is

$$
\begin{aligned}
\frac{W}{\frac{1}{2} E E^{2}} & =\frac{10^{6} \times 36 \pi}{\frac{1}{2} \times 5 \times 10^{-9}\left(40 \times 10^{6}\right)^{2}} \\
& =28.3 \mathrm{~m}^{3}
\end{aligned}
$$

The volume occupled by the gections, without considcration of the hollow mondrel and spacing, is

$$
\left(28.3 / 0.75 w^{3}-37.7 w^{3}-22^{-} g f\right.
$$

For extaple, if $l^{*}-1.2 \mathrm{~m}, \mathrm{f}=$ $0.14 \mathrm{~m}$, and $z=100$, than

$$
8=\frac{37.7}{2 \times 100 \times 0.14 \times 1.2}-1.125 \mathrm{a} \text {. }
$$

The grome volune $v=\frac{28.3}{0.65}=43.5 \mathrm{~m}^{3}$. The number of folls within the dimenaton $f$ io

$$
\frac{14 \mathrm{~cm}}{0.006 \times 2.54 \mathrm{~cm}}=918
$$

whlch we will round off at 920. The number of parallel subsectinl)s (stae Fig. 15) is $920 / 20=46$. We therefore, have 46 parallel subsections, each made of 20 fotls in sertes. He know that the capatt tance of the entire capactor should be $200 u F$ and we now check the capacitancs of the capacitor we have just designed.

$$
\begin{aligned}
c & =\frac{(\text { area }) \times 46}{(\text { chlckness) } 20} \\
& =\frac{2 F^{2}[\times 100 \times 46 / 20}{5 \times 10^{73} \times 2.5410^{-2}}=198 \mathrm{HF}
\end{aligned}
$$

where

$$
\begin{aligned}
& \text { chlckness }=5 n 11=5 \times 10^{-3} \mathrm{x} \\
& 2.54 \times 10^{-2} \mathrm{in} . \\
& \text { area }=2 \mathrm{ig}=2 \times 1.1 \times 1.125 \\
& 2=\text { number of vanes }=100 \\
& E\left(\text { castor o11) }=\frac{5 \times 10^{-9}}{24=}\right. \\
& Q=1.1 \mathrm{i} \\
& B=1.125 \mathrm{~m}
\end{aligned}
$$

\section{Inductance Constderations and Current}

\section{Crowding}

In order to make a capac1tor so that it has a margin of safety in ita performance, it is necessary not only to have it withstand the voltage but also for it to be able to carry the current without excessive heating of certain areas of the folls due to current crowding. "Current crowding" Is a phenomenon which manifesta ttself as an unusually hlgh currentdensity in certain regions of the 
1. 11 and in the tedetical connecti.us to the foll. This tnetriased current lenster in the regions of currout crowding , aluses large nagnet forees to act on the folls in conjabliom with a greatly inereased thermal stress due to the high $I^{2} R$ lorsess it these regtons. The comblation of these two types of stressis can cause the capacitor to fall. Tu huild a capacitor which is not subject to these difficultes we must exant ne the phenomenon of current crowding tn some detail.

In FIg. 17 we can see schematicaliy two folls connected in parallel to a bus. (Actually, there would be, typically, 40 parallal folls between each pair of folls shown.) The current flows on both stdes of each of these connected folls but ends up flowing on the outside surfaces of the bus. The Lurrent flowing on the Inside at the top of each foll has a magnetic field assoctated with it. This magnetic rield has to penetrate the foil, or curl around the edge of the foll with its assoclated current, in order to end up on the outside surface. This problem is not so serlous with only two folls connected to the bus, as depicted in Fig. 17, because the depth of penetration is typically equal to the foll thickness. But when as many as 40 foils are connected

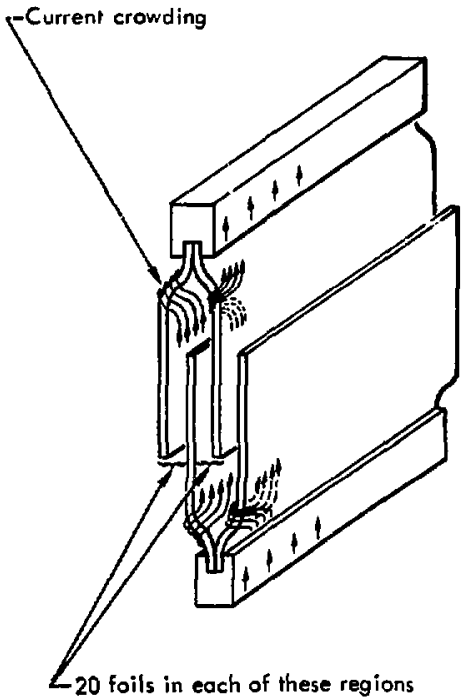

F18. 17. Fo1l cunnections to bus in high-ioltage capacitor.

to the bus, the current crowding would be severe because of the tortuous path which the Inner currents must take to get to the external surface. To solve the problem of current crowding, we propose to eliminate the muitifoll connections, as diagrammed in FIg. 18. As shown in Fig. 18 (top), the gap in the folls allows the electromagnet $1 \mathrm{c}$ energy to exit through the dielectric material only, thus preventing current concentrations. 


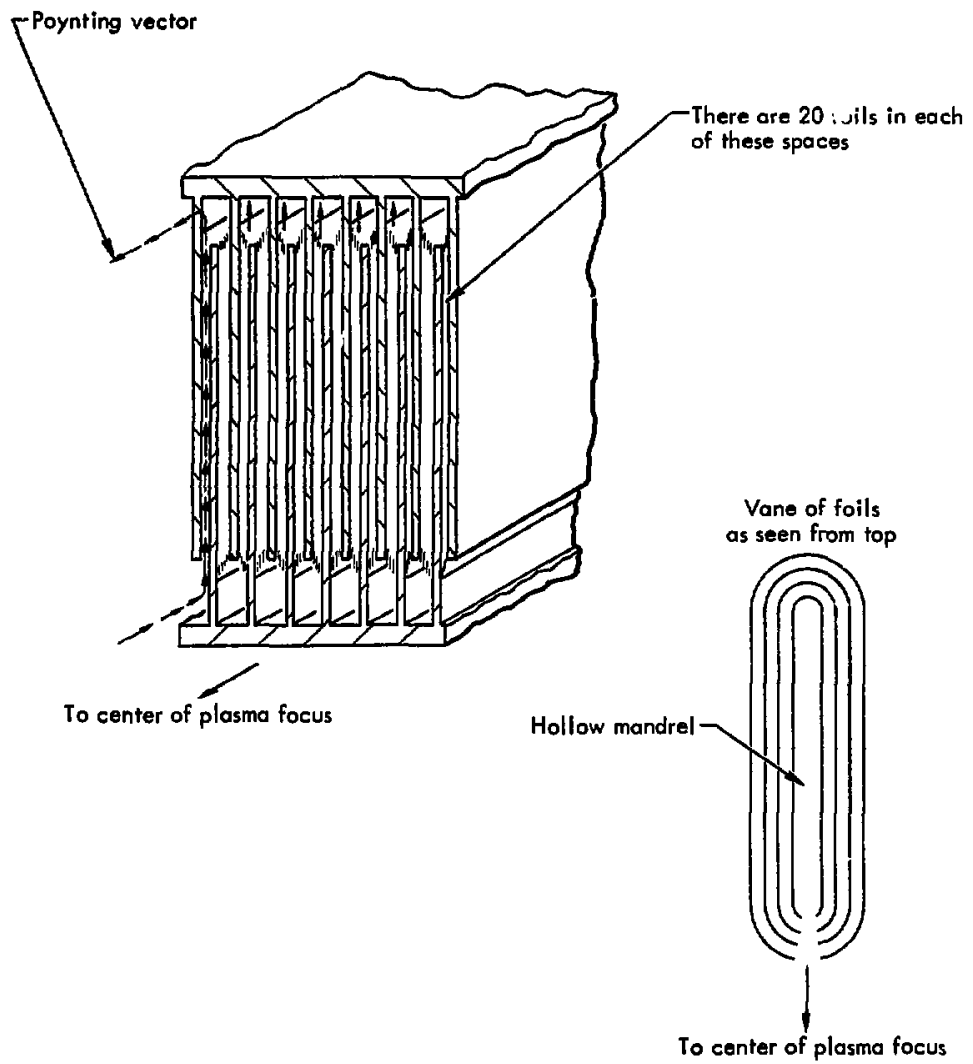

F1g. 18. Top and sectional viewg of typical high-voltage capacitor. 
In Fig. 18, also, capacitor subsection foils are shown where every 20 th foll is connected either to the top plate or the bottom plate. The direction of the Poynting vector is indicated by a dashed IIne. Note how the Poynting vector proceeds directly from the dielectric region to the load region without obstruction. Every twentleth foil (which is connected alternately to the top or botton plate) will be somewhat heavier than the others--about 4 mils thick (about $0.1 \mathrm{~cm}$ ) instead of 1 mi1. to provide physically stronger connections. The length and thickness of these connecting folls could be chosen to serve as protecting fuses. If part of the bank cries to dump into one shorted capacitor, these folls w111 heat up and thereby increase their resistance to the point where they become the predominant load, thus absorbing the energy in a non-destructive way.

As we have discussed in the Introduction, the 16-fold volume increase necessary to reduce voltage stress puts severe 1Imitations on our ability to design the entire bank for low inductance. In the following paragraphs, we develop a bank configuration with very low inductance.

We now determine the inductance that the capacitor presents to the discharge current. Figure 19 is a schematic representation of the plasma-focus capacitor, switches, parallel-plate transmisston 1 ine and the plasma focus itself.

We first compute the Inductance associated with the entire volume occupied by the capacitor bank in the absence of the capacitrr vanes. This will give us the extreme upper limit for the bank itself. Assume a path for the current $I$, flowing down at $\mathbf{r}_{0}$ and up at $r_{3}$. The Inductance, $\mathrm{t}_{A}$, will be due to the annular volume enclosed by $\left(\pi r_{3}^{2}-\pi r_{0}^{2}\right)$. In the region $r_{0}<r<r_{3}$, the magnetic field $H_{\theta}$ due to the current $I$ is

$$
B=\mu_{0} I / 2 \pi r T
$$

where

$$
\mu_{0}=4 \pi \times 10^{-7} \mathrm{H} / \mathrm{m} \text {. }
$$

The magnetic flux $\begin{aligned} \phi & =\int_{r_{0}}^{r_{B}} B d r \\ =\frac{\mu_{0} I \ell}{2 \pi} & \int_{r_{0}}^{r_{3}} \frac{d r}{r}=\frac{\mu_{0} I \ell}{2 \pi} \ln \frac{r_{3}}{r_{0}}\end{aligned}$

$$
\phi=2 \times 10^{-7} \mathrm{Il} \ln \frac{\mathrm{r}_{3}}{\mathrm{r}_{\mathrm{o}}} \mathrm{Wb} \text {. }
$$

Therefore,

$$
L_{A}=\frac{\Phi}{I}=2 \times 10^{-7} \& \ln \frac{r_{3}}{r_{0}} H .
$$

Now we compute the Inductance assiciated with the same volume, wher the current $I$ flows down at $r_{0}$ (in Fig. 19) but flows back up along 


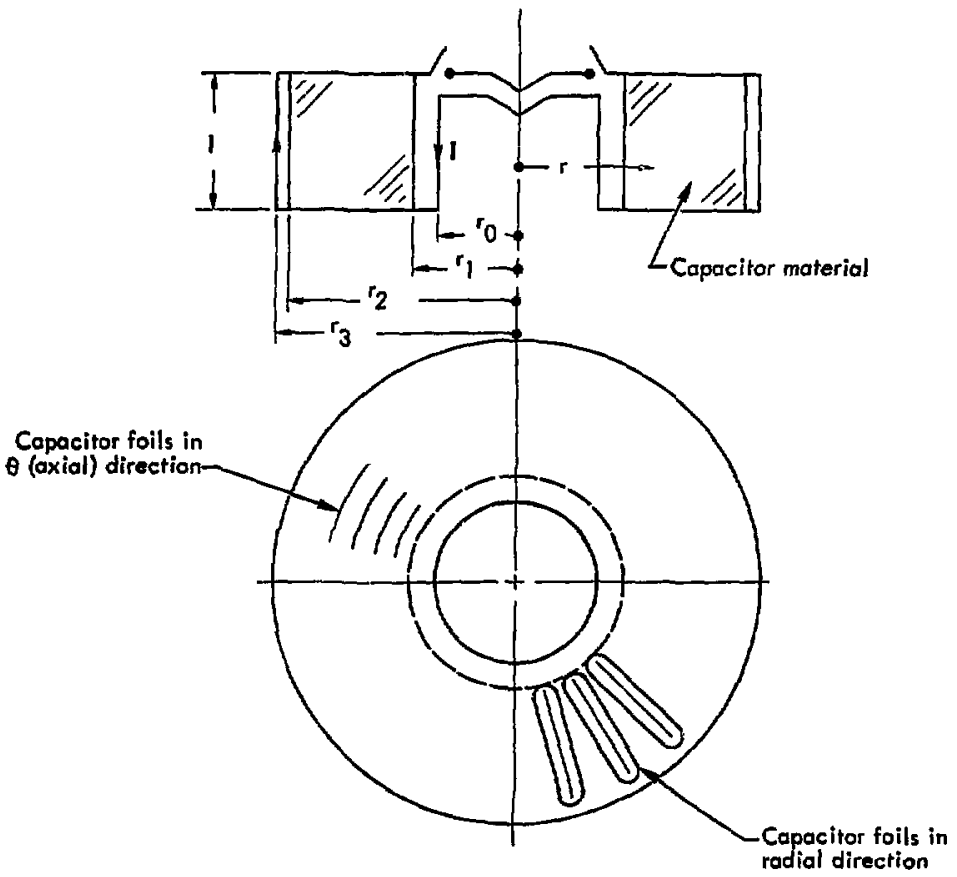

Fig. 19. Schenatic representation of plasma-focus capacitor, switches, parallel-plate transmission line and plasma focus itself.

the entire radius $\left(r_{0}<r<r_{3}\right)$ with a uniforw current density.

This computation will give us an estrmate of the Inductance assocfated with the volune fllled with capacitor folls but allowing mutual flux to couple all currents.
That 1s,

$$
f(r)=\frac{-I}{\pi\left(r_{3}^{2}-r_{0}^{2}\right)} .
$$

Then

$$
\begin{aligned}
H \cdot 2 \pi r & =I-J \int_{0}^{i} 2 \pi r d r \\
& =I-j \pi\left(r^{2}-r_{0}^{2}\right)
\end{aligned}
$$


and

$$
\begin{aligned}
H & =\frac{I}{2 \pi r}\left(\begin{array}{r}
1-\frac{r^{2}-r_{0}^{2}}{r_{3}^{2}} r_{0}^{2}
\end{array}\right) \\
& =\frac{I}{2 \pi r}\left(\frac{r_{3}^{2}-r^{2}}{r_{3}^{2}-r_{0}^{2}}\right)-H_{B} .
\end{aligned}
$$

The inductance $L_{B}$ assoclated with this current configuration,

where $\phi=\int_{0}^{r^{3}} \mu_{0} H \ell d r$,

1s,

$$
\begin{aligned}
\mathrm{L}_{B}= & 2 \times 10^{-7}\left[\left(\frac{r_{2}^{2}}{r_{3}^{2}-r_{0}^{2}}\right)\right. \\
& \left.\ln \frac{r_{3}}{r_{0}}-1 / 2\right] H .
\end{aligned}
$$

Now let us compare $L_{B}$ and $L_{A}$ :

$$
\begin{aligned}
\frac{L_{B}}{L_{A}} & =\frac{r_{3}^{2}}{r_{3}^{2}-r_{0}^{2}}=\frac{1}{\ln \frac{r_{3}^{2}}{r_{0}^{2}}} \\
& \left(\frac{r_{2}}{r_{0}}\right)^{2} \\
& \left(\frac{r_{2}}{r_{0}}\right)^{2}-1
\end{aligned}
$$

Representative values for the bank's volume are: volume $-43.5 \mathrm{~m}^{3}$, $r_{2}-r_{1}=1.125 \mathrm{~m}$, and $\ell^{\prime}=1.2 \mathrm{~m}$. Then,

$$
\begin{aligned}
\frac{43.5}{\ell^{\prime}} & =\pi\left(r_{2}^{2}-r_{1}^{2}\right) \\
& =\pi\left(r_{2}-r_{1}\right)\left(r_{2}+r_{1}\right)
\end{aligned}
$$

$$
\begin{aligned}
r_{2}+r_{1} & =\frac{36.25}{\pi 1.125}=10.25 \\
& =1.125+r_{1}+r_{1} \\
2 r_{1} & =9.13 \\
r_{1} & =4.56 \mathrm{~m}
\end{aligned}
$$

and

$$
r_{2}=5.7 \mathrm{~m}
$$

Thus, for $r_{0} \approx r_{1}$ and $r_{3} \approx r_{2}$ we have

$$
\frac{r_{3}}{r_{0}}=\frac{5.7}{4.56}=1.25 \text { and }\left(\frac{r_{3}}{r_{0}}\right)=1.55 \text {. }
$$

Therefore,

$$
\begin{aligned}
\frac{L_{B}}{L_{A}} & =\frac{1.55}{0.55}-\frac{1}{\ln 1.55}=2.8-2.28 \\
& =0.52 .
\end{aligned}
$$

Thus the return of the current $I$ with a uniform current density throughout the volume of the capacitor reduces the Inductance to about 0.52 of $L_{A}$. The values of $\mathrm{H}_{A}$ and $\mathrm{H}_{\mathrm{E}}$ as $\mathrm{a}$ function of radius (r) are plotted in Fig. 20. If the foils of the capacitor are run in the $\theta$ direction, as shown In Fig. 19, the value of $\mathrm{H}_{\theta}(\mathrm{r})$ will be as shown by $H_{C}$ in F18. 20. The corresponding inductance $L_{C}$ will be very similar to $L_{B}$. If, however, the folls of the capacitor run predominantly in the radial direction, as shown in $F I_{g}$. 19, the foils are perpendicular to $\mathrm{H}_{\mathrm{G}}$, the fleld produced by the load current. It is the field $H_{\theta}$ whtch 


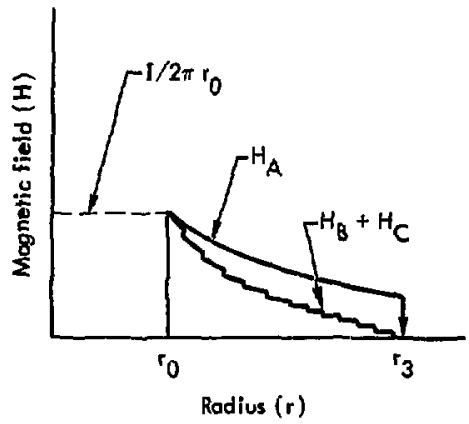

Fig. 20. $H_{A}, E_{B}$ and $H_{C}$ ve radius.

the previous geometries have fatled to reduce. To a first approximation (a thorough field solution is given in Append $1 x$ A), since the dc fleld solution requires that $H$ run perpendicular to all the 100,000-odd foils, c. e dc solution does not apply to the ac case. For the case in which the folls run in the $\theta$ direction, the dc and ac field solutions are similar and the flux occupies the entire fotl region. To a first approximation for the radially oriented folls, the magnetic flux is completely excluded from the foll region. of course, $H_{\theta}$ exists in the region between $I_{0}$ and $r_{1}$ and the region between $r_{2}$ and $r_{3}$ and some of this field does penetrate between the folls, as shown in Append $1 \times A$. The Inductances in the regions $r_{0}$ to $r_{1}$ and $x_{2}$ to $r_{3}$, are deatgnated $L_{1}$ and $L_{3}$ reapectively.
From Appendix A

$$
\begin{aligned}
& L_{1}=0.485 \times 10^{-7}, \ln \frac{r_{1}}{r_{0}} H \\
& L_{3}=0.485 \times 10^{-7}, \ln \frac{r_{3}}{r_{2}} H,
\end{aligned}
$$

and the vane region inductance is

$$
\mathrm{L}_{2}=\frac{2.46 \times 10^{-7} \ell^{\prime}}{20} \mathrm{H} \text {, }
$$

where

$$
2 \mathrm{~N}=\text { number of vanes. }
$$

For the proposed radtal packing (Fig. 21; the radius $r_{1}$, must allow 100 vanes around the circumference. Thus, since the width of each vane 1s $30 \mathrm{~cm}\{2 \times(14+1)\}$ the circumference must be $30 \mathrm{~m}$.

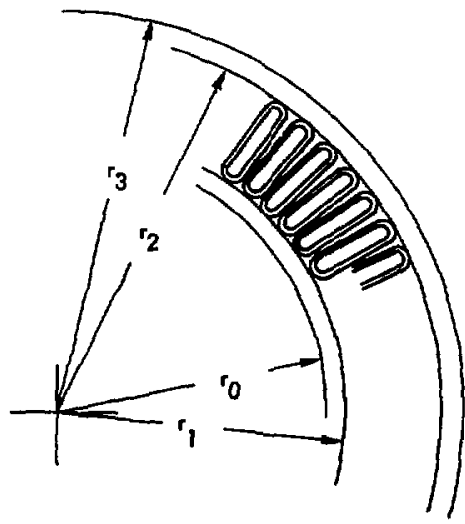

F1g. 21. Radtal vo axial foll placement in high-voltage capacitur. 
Therefore

$$
r_{1}=\frac{30}{2 \pi}=4.77 \mathrm{~m} \text {. }
$$

The mintmum $r_{1}$ from volume consideractons is $4.56 \mathrm{~m}$. We w111 select a destgn value of $4.8 \mathrm{~m}$ for $r_{0}$ and a value of $6 \mathrm{~m}$ for $\mathrm{r}_{3}$. Thus,

$$
\begin{aligned}
& L_{A}= 2 \times 10^{-7} \ell^{\prime} \ln \frac{r_{3}}{r_{0}}=2 \times 10^{-7} \\
& \times 1.2=\ln \frac{6}{4.8}=53 \mathrm{nH} \\
& L_{B}= 0.52 L_{A}=28 \mathrm{nH} \\
& L_{C} \approx L_{B}=28 \mathrm{nH} \\
& L_{1}=48.5 \times 10^{-9} \times 1.2 \ln \frac{4.85}{4.8} \\
&=0.48 \mathrm{nH} .
\end{aligned}
$$

and

$$
\begin{aligned}
L_{3} & =48.5 \times 10^{-9} \times 1.21 \pi \frac{6}{5.965} \\
& =0.34 \mathrm{nH} .
\end{aligned}
$$

To calculate $L_{2}$ we have to choose the proper number of folls. The total number of foils ts $20 \times 46 \times 100=92000$. However, we have 200 gaps $1 \mathrm{~cm}$ wfde between the sectlons and in the mandrel. For an excremely conservative estimate let us decrease the density of fofls to provide $1 \mathrm{~cm}$ gaps between each 2 foils. For a $30 \mathrm{~m}$ clrcumference with gapa of $1 \mathrm{~cm}$ the number of foils (2N) equals 3000 . That is,

$$
\begin{aligned}
L_{2} & =\frac{2.46 \times 10^{-7} \times 1.2}{3000^{-7}} \\
& =9.8 \times 10^{-11} \mathrm{H} .
\end{aligned}
$$

Thus the total Inductance of the bank is $\mathrm{L}_{1}+\mathrm{L}_{2}+\mathrm{L}_{3} \approx 0.9 \mathrm{nH}$. This represents a small contribution to the system total.

The Inductance of the transmissfon IIne, the switches, and the stepped Inductor must be added in. For a 0.3 $\mathrm{cm}$ spacing between the parallel-plate transinsion 1ine plates, the Inductance of the transmission ine $1 \mathrm{~s} 0.3 \times 2 \times \ln \frac{4.8}{0.5}=1.36 \mathrm{nh}$.

The switch inductance will be calculated on the basis of using 2 In diameter SCR chips 0.5-mn thick. Thus,

$$
\begin{aligned}
\text { L/wefer }= & 0.1 \times 10^{-9} \\
& \left(0.5+\ln \frac{3.54}{2.54}\right)
\end{aligned}
$$

$$
=8.3 \times 10^{-11} \mathrm{H} / \text { wafer. }
$$

Since there are 100 wafers in sertes and 100 switches in parallel the total switch inductance is $8.3 \times 10^{-11} \mathrm{H}$.

The Inductance of the stepped Inductor when saturated is:

$$
\mathrm{L}=\frac{\mu_{\mathrm{o}}}{2 \pi} \times 2 \times 10^{-2} \ln \frac{167}{100}=2 \mathrm{nH} .
$$

The total inductance of the bank, switch, transmission line, and stepped inductor (saturated) is:

$$
\begin{aligned}
L_{\text {Total }} & =0.9 \mathrm{nH}+1.36 \mathrm{nH}+ \\
& 0.1 \mathrm{nH}+2.05 \mathrm{nH} \\
& =4.41 \mathrm{nH} .
\end{aligned}
$$


We propuse to make a sma11-scale electrical mock up of the capacitor bank and check the Inductance at the appropriate frequency to verify our inductance calculations for the capacitor.

POWER SOURCE AND CHARGING CIRCUIT

The pulsed-plasma-focus neutron and radiation facility will be operated at one pulse per second at an average power expendtture of $1 \mathrm{MH}$. It should be feastble to purchase this extra power from local utilities. Considering the energy crisis, the extra lines to be bullt, the large interference with normal utility operations and the buffer costs, it would be more advantageous to have our own stationary power source. A conventent source would be a compact gas turbine generator set, similar to the type power companies use for peak energy shaving. We therefore propose a gas turbine stationary energy source charging an intermediate capacitor bank, as shown in Fig. 22.

Waveforms showing the timing of this circuit (on a logarithmic time scale) are ohown in FIg. 22. In this circult we take advantage of the unidirectional properties of the SCR switch which stops the ringing of the bank with the SFG load after $1 / 2$ cycle. Thus all the energy not consunted in the focus ends up in the bank with opposite polarity. Typically this energy amounts to half of the initlal bank energy. In the circuit of Fig. $22 C_{B}$ In series with $C_{s}$ and $L$ can $r i n g$ only $1 / 2$ cycle because of diode $D$. If the values are properly chosen, at the end of the $1 / 2$ cycle $C_{B}$ will be charged to the Initial required voltage and be ready to fire, and $c_{s}$ will be completely discharged. If this rtinging is performed in $10 \mathrm{msec}$, then the charging current to $C_{B}$ will be a few thousand amps, which is reasonably low. Typical parameters, assuming $50 \%$ energy loss In the focus, are shown in Fig. 22. For this case $c_{s}$ is $1166 \mu F$ and $V_{s}$ is $29.3 \mathrm{kV}$.

\section{SWITCHING}

The switch requirements for the SFG energy source are relatively easy to meet Individually, but collectively they are beyond the current state of the art.

The general switch requirements are to hold off $100 \mathrm{kV}$ in the forward direction and conduct $10^{7}$ A for 3-4 us after closing. The switch must be able to operate at a repetition rate of at least one pulse per second for approximately $10^{7}$ shots. Finally, the switch Inductance should not be 

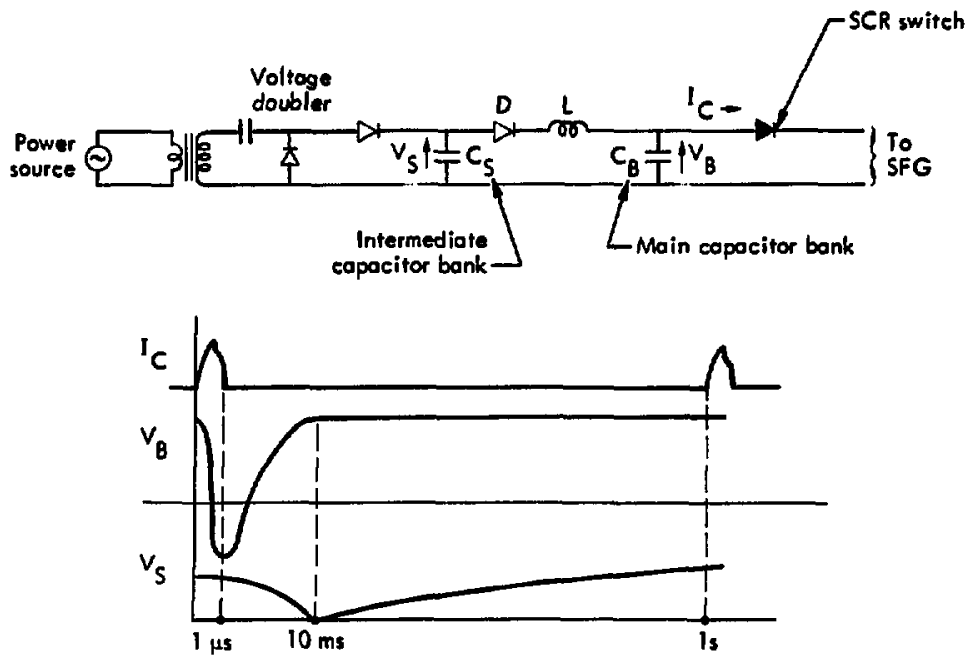

Fig. 22. Power source simplified schematic and timing diagram.

larger than a fraction of $1 \mathrm{nH}$.

The peak power requirement in Itself is not difficult to meet. A single h1gh-pressure spark gap can block $100 \mathrm{kV}$ and conduct $100 \mathrm{kA}$ for a few microseconds and have an Inductance below $100 \mathrm{nH}$ so that the desired requirement can be met by 100 such parallel switches. However, the Iife of these switches cannot be atretched much above $10^{4}$ shots ( 3 hours). Electrode erosion and the deposition of electrode material on che Insulating walls of the owitch are the cause for the limited Iffe expectancy. A further 11mitation is imposed by the high average power requirenent ( $1 \mathrm{MW}$ ) that the switch has to transfer. Typically, these switches absorb between 0.1 and $1 \%$ of the energy they transfer. Thus, as much as $10 \mathrm{~kW}$ of heat has to be removed, thus Imposing a further ilditation on the use of these switches in the design of the capacitor batik.

We have Invest Igated all potent1al candidates for this switching application such as the vacuum switch, Ignitrons, thyratrons, 
high-pressure spark gapg, liquid (oll and water) dielectric gaps, soliddielectric switches, and solid-state suitches.

Thyratrons and Ignitrons are ruled out because of power, Inductance and longevity Iimitations.

Short Iffe, high Inductance, and low average power rule out the vacuum spark-gaps, h1gh-pressure spark gaps, and the solid dielectric switches. It appears that the only useful candidates are the liquiddielectric and the solid-gtate switches.

A liquid-dielectric switch is shown In FIg. 23. The close spacings permitted by the immersion of the assembly in transformer ofl and the Inoulating and heat-exchange properties of the ofl make the switch relatively sma11 and compact. The liquid dielectric is "self healing" and the transformer ofl w $\$ 11$ be pumped continuously through a filter to remove any contamination which would otherwise bulld up. Large rotatable electrodes provide ample surface area for erosion and thus assure long life.

The most promiaing owitch, however, is the solid scate device. A very Important advantage is that eemiconductor devices have practically I1mitless $11 \mathrm{fe}$. Currently-manufactured silicon controlled rectifiers ( $\left.\operatorname{SCR}^{\prime} \theta\right)$,

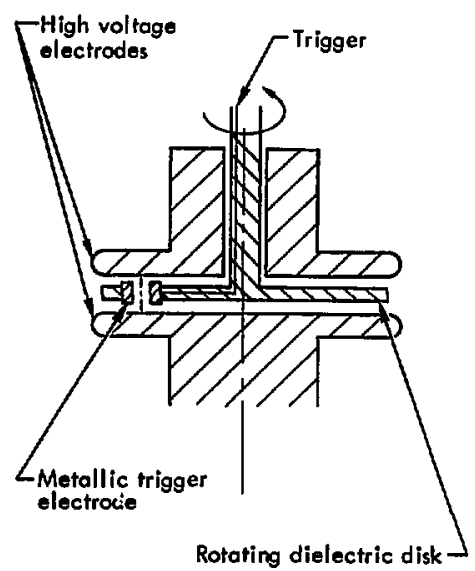

Note: Switch is immersed in oil

Fig. 23. 011-immersed rotatingelectrode high-energy switch.

In particular, are capable of holding off 1000 to 2000 volta per unit, with current-carrying ability, In the sinusoldal steady state, of approximately $1000 \mathrm{~A}$. This power level is too small for our application. However, in the turn-on regime of $10^{-4} \mathrm{~s}$, a wafer about $0.5-\mathrm{m} ! \mathrm{l}$ ch $1 \mathrm{ck}$ and 2 Inches in dlameter can carry 100,000 to $200,000 \mathrm{~A}$ for a short perlod of time. These devices are st111 not satisfactory for our requirements because the turn-on time is much too slow. 
Recently, however, grent advances have been made in turn-on-time characteristics. In particular, development by the Westinghouse Research Laboratorlest has shown that direct optical triggering makes the SCR a prime candidate for our application. In their method of trlggering, a laser beam, matched to the silicon wafer band gap, illuminates the wafer thus generating electron-hole pairs necessary for conduct ion.

To date, a 40,000 A/ $\mu \mathrm{s}$ current rise has been achieved. This rate is due to external-circultry limitation rather than device Ilmitation. Thus such a device will provide $100,000 \mathrm{~A}$ in $3 \mu \mathrm{s}$, the time necessaxy for the discharge of the capacitor bank into the plasma focus device. Thus, 50 to 100 such units in parallel will carry the total 5 to $10 \mathrm{MA}$ necessary to energtze the plasma-focus device. Since the voltage-holding capabllity of the wafer is only 1 to $2 \mathrm{kV}$, we need, again, 50 to 100 such units in serles. The laser-beam inftiated

*Reference to a company or product name does not Imply approval or recommendation of the company or product by the University of California or the U.S. Energy Research \& Development Administration to the excluston of others that may be suitable, turn-on time has been successfully demonstrated for such large series arrays. Since the turn-on time 18 pracelcally instantaneous, there is no avalanche fallure. Thus the total number of wafers needed for our switch is five- to ten-thousand wafers.

The Inductance of these wafers 18 extremely small. This is because the current flows through the total area of the wafer. Consequently, the current path occuples a large cross-sectional area. Such an array of 10,000 wafers will be arranged to be part of the cransmission-line geometry so as to minimize the self inductance. In fact, we can make this Inductance almogt negligfble. See FIg. 24.

For these 10,000 units we need approximately 10 to $100 \mathrm{~J}$ of Iaser power delivered within 20 ns. This can be easily achieved with a single laser oaclilator and ten 10-joule amplifiers. To date, the cost of the SCR wafers is in the region of $\$ 100$ each. This is with the purchase of eingle units. Thus the cost of the silficon wafers alone would be in the nelghborhood of $\$ 1,000,000$. If we include the laser and mounting cogts and the large-quantity purchase price reductions for the silicon, we can estimate the switch price between one and two million dollara. 


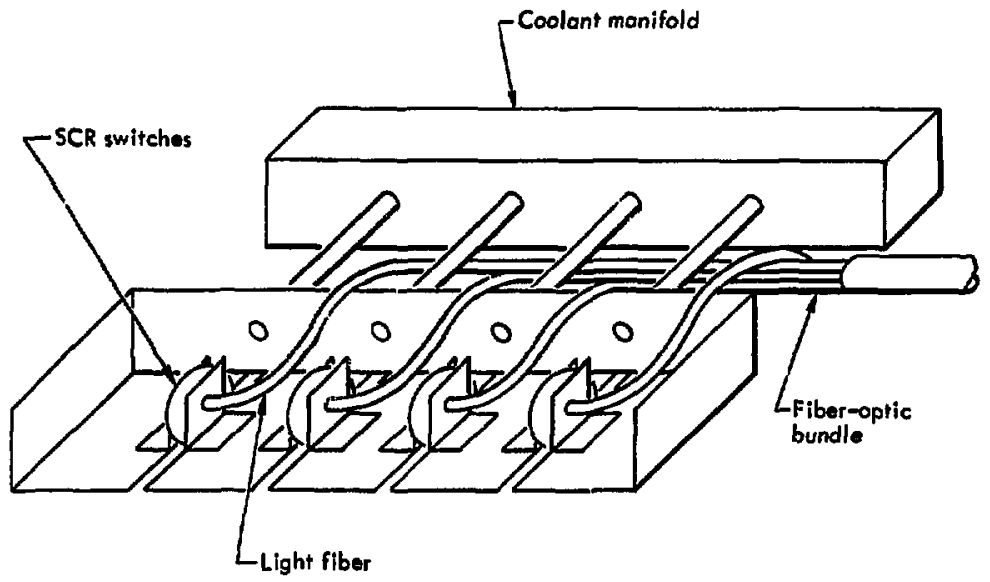

F1g. 24. Construction detail of optically triggered solid-state owitch.

For comparison with conventional for aur applications. Hence, we switches (high-pressure spark gaps) Table 3 indicates that even with only 10 atilion discharges for the SCR ayaten, it is between a factor of 50 to 100 times cheaper than a hIgh-presaure spark gap.

Thus, the 1ight-activated SCR 18, by far, the most logical chaice have inftiated negotiation with Weatinghouse on the development of such a suitch tallored to our applfication, and a proposal has been submitted by them to develop a prototype. As shown in the previous section, a $10^{4}$ wafer unit having a total inductance of less than 0.1 nh is more than adequate for the job. 
Table 3. Inductance per un 1 t

\begin{tabular}{|c|c|c|c|c|c|c|c|c|c|}
\hline & v/unit & I/unit & $\begin{array}{c}\text { Power / } \\
\text { unlt }\end{array}$ & $\begin{array}{l}\text { Induct- } \\
\text { ance }\end{array}$ & $\begin{array}{l}\text { No. of } \\
\text { units } \\
\text { needed } \\
\text { for } 10^{12} \\
\text { watts }\end{array}$ & $\begin{array}{l}\text { Shots } \\
\text { unit }\end{array}$ & $\begin{array}{l}\text { Nu, of } \\
\text { units } \\
\text { needed } \\
\text { for } 1012 \\
\text { watts } \\
\text { and } 10^{7} \\
\text { shots }\end{array}$ & $\begin{array}{l}\text { Cost } \\
\text { per } \\
\text { unft } \\
(s)\end{array}$ & $\begin{array}{l}\text { Tota1 } \\
\text { cost } \\
(\$)\end{array}$ \\
\hline $\begin{array}{l}\text { High } \\
\text { Pressure } \\
\text { spark gap }\end{array}$ & $10^{5}$ & $10^{5}$ & $10^{10}$ & $\begin{array}{c}100 \\
\mathrm{nH}\end{array}$ & $10^{2}$ & $10^{4}$ & $10^{5}$ & 1000 & $10^{8}$ \\
\hline $\mathrm{SCR}$ & $10^{3}$ & $10^{5}$ & $10^{8}$ & $\begin{array}{c}.001 \\
\mathrm{nH}\end{array}$ & $10^{4}$ & $10^{7}+$ & $10^{4}$ & 200 & $2 \times 10^{6}$ \\
\hline
\end{tabular}

\section{Research and Development}

SHORT RANGE DEVELOPMENT

Listed below are the technical problems which must be solved to assure reliable, continuous operation of a fuston reactor simulator capable of delivering $10^{15}$ DT neutrons per second.

High Voltage Operation of the SFG

It Is clear that the optimum conditions for formation of the current sheet in plasma-focus devices are quite different from the optimum conditions for driving the current sheet after it is formed. It is known from experiments and theory that a too rapid current Increase during current-sheet formation results in an instabllity which prevents formation of a uniform plasma. Conversely, a rapid current rise is desirable in order to obtain a high peak current. To meet these requirements we have proposed a stepped-Inductance system which provides a high initial external Inductance and low Inductance after the current sheet is formed. This system should permft the use of smaller guns, higher bank voltage and higher peak current. As an Initial step we suggest the installation of 80 to $100 \mathrm{kV}$ capacitors on our present SFG device as soon as possible in order to gain early operational experience with a high voltage syatem. We also propose 
to start life-testing components of the repetitively pulsed $1 \mathrm{MJ}, 1 \mathrm{pps}$, capacitor bank at voltage from $100 \mathrm{kV}$ to $400 \mathrm{kV}$, to accumulate experlence on the life of these capacitors at higher voltages.

\section{Switch Development}

The development of $1 \mathrm{ight-}$ activated gilicon switches is now in progress at Westinghouse Research Labs. The operation of large sertesparallel arrays of these switches must be proved feasible.

Concurrently, the devalopment of a liquid-die:ectric switch must be undertaken to provide a sultable alternative to the light-act Ivated silicon switcher,

\section{Long-Life Capacitor Bank}

Component development and testing for the proposed capacitor bank must be undercaken with careful attention given to the radiation problem. An Important aspect of the radiation problem is the determination of capecitor shlelding requirements with reapect to longevity.

\section{Electrode Erosion}

Electrode eroation in the plasma focus is cumulative. Thus geometrical electrode arrangeant and techniques of feeding new electrode material must be developed and teated to alleviate the erosion problem. The solut ion reached must not cause degradation of the focus performance.

Insulator Development

The Insulator In the plasma focus provides the initial breakdown surface for the plasma sheet. To provide adequate lift-oif of the plasma sheet and minimize restrike problems the insulator must maintain its integrity over many shots. Unt 11 now, Pyrex glass has been the choice of most investigators. However, it seems quite 11kely that for a repetitive by pulsed application a more refractory insulator will have to be developed.

\section{LONG RANGE RESEARCH}

In addition to the above shortrange development plan, it is also proposed that more fundamental research be inftiated to increase neutron- and plasma-wind yield. For several years LLL has studfed fundamental changes in plasma-focus operation which are almed at increasing efficlency and wilch have the ultimate goal of achleving breakeven fugion. Obviously, it is not necessary to achleve breakeven fusion to increase greatly the utility of the plasma focus. He belleve we can, with highet energy systems, achieve 
approximately $10^{17}$ DT meucrons in short pulses once we improve our understanding of the neutron-producing mechanisms of the DPF.

The nature of the process which energizes deutrons so that they produce neutrons in the plasma focus is certainly not understood or agreed upon by all plasma-focus finvestigators. In the calculations of the scaling of nevtron yisld with current in the plasma focus, a Bennett relation, $I=200 \mathrm{NkT}$, Is usually assumed. It is also assumed for the most part, that the plasma is a thermal ensemble which has been heated by adiabatic compression of its cylindrical shape to a small radius. However, the anisotropy of the neutron energy and the appearance, reported by several observers, of two neutron pulses approximale'y 100 to 200 ns wide, spaced by $300 \mathrm{~ns}$, makes this stmple adlabatic-compression picture untenable.

Investigators at Stevens Institute of Technology and the Instituto
Electrotecnico Nazionale In Turin, working wit! small plasma-focus machines, have shown that the $x$-rays come from localized "apple-core"shaped volumes as small as $50 \mathrm{\mu m}$ in diameter. The number of shortduration neutron and $x$-ray pulses (approximately $10 \mathrm{~ns}$ in duration) agrees on the average with the number of locallzed $x$-ray spots. The shortduration neutron pulses are obtalned only with the neutron scintillator very close to the plasma focus (approximately $15 \mathrm{~cm}$ ). It appears that we can draw a fairly firm conclusion that the $x$-rays and neutrons in these small machines come from localized concentrations of plasma which live for ibout $10 \mathrm{~ns}$ each. As the neutron and $x$-ray production in these small plasma-focus machines Increases with increased voltage on the machine, however, the question remains whether the Increased neutron and $x$-ray production is due to a greater multiplicity of locallicedconcentraced sources or to a greater strength of each source.

\section{Acknowledgments}

Thanks are due to H. M. Graham for contributing his valuable knowledge and experfence of capacitors in the development of this design. Also, the authors wish to express their thanks to R. M. Bevensee for his work in preparing Appendix $A$ on stored magnetic energy in a eircular vane structure. 


\section{References}

1. W.H. Bostick, V. Nardi and W. Prior, J. Plasma Phys. 9, 7 (1972).

2. R.F. Post, Physics Today (Apr11, 1973).

3. Proc. Annu. Mtg. Div. Plasma Phys. of Am. Phyg. Soc., 15th, Section 4h, in Bull. Am. Phys, Soc. (October, 1973), p 1318.

4. H. Rapp, Phys, Lett, 43A, 420 (1973).

5. V.S. Imshenntk, N.V. Filippov and T.I, Filippov, Nucl. Fusion, 13, 929 (1973).

6. 1. Michel, K.H. Schönbach and H. Floher, Appl. Phys. Lett, 24 (2), 57 (1974).

7. D.A. Fretwald and J.N. Downing, A Survey of a 210-kJ Dense Plasma Focus (DPF-6), Los Alamos Scientific Laboratory, Rept. LA-5635-MS (1974).

8. V. Nard1, Physical Rev. Lett. 25, 11 (1970).

9. v. Nard1, Proc. Europ. Conf. on Controlled Puston and Plas. Phys, 5th (Grenoble) paper 163, E5 (1972).

10. D.R. Wells and J.N. Norwood, Phys. Fluids 7, 1582 (1968).

11. D.R. Wells, J. Plasma Phye. 4, 645 (1970).

12. D.R. Wells, J. Plasma Phys. 3, 21 (1969).

13. W. Bootick, V. Nard1, W. Prior and F. Rodriquez-Trelles, "On the Nature of Highly Localized X-Ray Sources in the Plasma Focus," In Proc. Topical Conf. on Pulsed High-Beta P1asmag, 2nd, (Garching, 1972), p 155.

14. I.F. Belyaeva and N.V. Filippov, Nuclear Fusion 13, 881 (1973).

15. H. Conrads, P. Cloth, M. Demmler and R. Hecker, Phys. Fluids 15 (1), 209 (1972).

16. J.H.Lee and D.R. McFarland, Bu11. Am. Phys. Soc. 17, 1023 (1972).

17. W, H. Bostick, V. Nard1 and W. Prior, Annals New York Acad. Sc1. 251, 2 (1975). 


\section{Appendix A}

\section{Estimation of Internal Stored Magnetic Energy in a Circular Vane Structure}

Cross-sectional and partial top views of the vane structure are shown in Fig. A-1. This structure will be examined as a parallel RLC circuit oscillating as a high $Q$ circuit after the switches are closed between the vanes and center post. Each vane consists of numerous parallel plates connected alternately to the top and battom of the structure and is charged Inttially before the switches are closed. Let the total capacity of all the vanes in parallel be $C_{T^{*}}$ When the switches are closed,

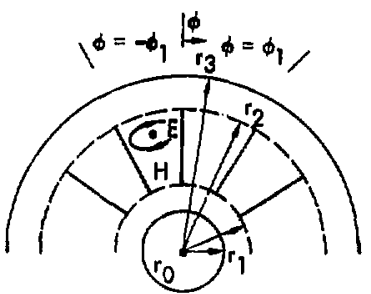

Top view, showing labeling of dimensions. the vanes discharge through the center post and the outer guard ring (which may be connected or not, along the dashed surface in F1g. A-1; the difference is a negligible fringIng capacitance) and they dissipate energy in the walls. The stored magnetic energy between the vanes oxa in the ir.ner and outer gaps represente an inductance $L_{T}$ in parallel with $C_{T}$ and the effective conductance $G_{T}$. As the vanes discharge, the total current through the center post varies essentisilly as $\exp \left(-G_{T} t / C_{T}\right) \cos \omega_{0} t, t \geq 0$.

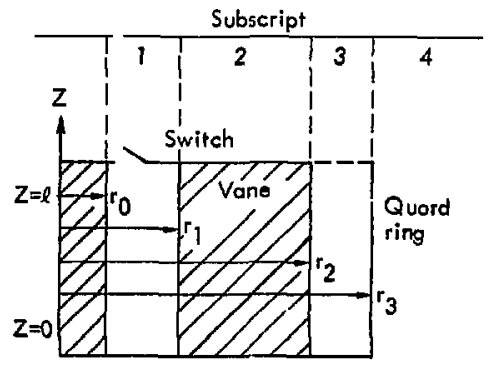

Cross-section through o vane.

Fig. A-1. Circular vane atructure. 
We shall estimate the relative amounts of stored magnetic energy in the caps and in the vane region $r_{1} \leq \mathbf{r} \leq \mathbf{r}_{2}$. To do this, we shall make the practical assumption that $C_{T}$ is so large that the resonant wavelength $\lambda_{0}$ is far larger than the largest dimension of the system.
To determine the various contributions to inductance $L_{T}$ we neglect the variation with $z$ of the primary fleld quantities and assume $\partial / \partial \phi=0$ in the gaps, where $r_{0} \leq r \leq r_{1}$, $r_{2} \leq r \leq r_{3}$. Maxwell's equations then determine the primary fleld quantitles within the inner gap (subscript 1) as

$$
\left.\begin{array}{l}
E_{Z I}=A_{1}\left[J_{0}(k r)-\frac{J_{0}\left(k r_{0}\right)}{Y_{0}\left(k r_{0}\right)} Y_{0}(k r)\right] \\
H_{\phi 1}=j A_{1}\left(\frac{\varepsilon}{\mu}\right)^{1 / 2}\left[J_{1}(k r)-\frac{J_{0}\left(k r_{0}\right)}{Y_{0}\left(k r_{0}\right)} Y_{1}(k r)\right]
\end{array}\right\} \begin{gathered}
r_{0} \leq r \leq r_{1} \\
\text { all } \phi
\end{gathered}
$$

where $E_{2} 1 \equiv 0$ at $r_{0}$, and $k=\omega_{0} / c=2 \pi / \lambda_{0}$.

The magnetic field vector $\overline{\mathrm{B}}$ within one of the vane gaps behaves qualitatively as shown in $\mathrm{Flg}$. A-1;

It consists of $\mathrm{H}_{\boldsymbol{T}}$ - and $\mathrm{H}_{\phi}$-components. We seek a simple solution to Maxwell's equations at frequency $\omega_{0}$ in the vane region $r_{1} \leq \tau \leq \tau_{2}, 0 \leq \phi \leq \phi_{1}$ so that $\overline{\mathrm{H}}$ and the Implied $\mathrm{F}_{Z}$ w111 satiafy the boundary condition of $E_{2}=0$ at $\phi-0, \phi_{1} \cdot E_{2}$ satisfies the wave equation, and in cylindrical coordinates with $\partial / \partial 2$ = 0 this equation de.. fines the Bessell function $J_{\mathrm{N}}$ or Neumann function $Y_{N}$, with $N \equiv \pi / \phi_{1}$. So In that vane region, (Bubscript 2)

$E_{Z 2}-\left[A_{2} Y_{N}(k r)+A_{3} J_{N}(k r)\right]$ BIn $N \phi(2 a)$

$$
\begin{aligned}
H_{r 2}= & \frac{\mathcal{J}}{\omega \mu} \frac{N}{r}\left[A_{2} Y_{N}(k r)\right. \\
& \left.+A_{3} J_{N}(k r)\right] \cos N \phi
\end{aligned}
$$

$$
\begin{aligned}
H_{\phi 2}= & -j\left(\frac{E}{\mu}\right)^{1 / 2}\left[A_{2} Y_{N}(k r)\right. \\
& \left.+A_{3} J_{N}(k r)\right] \sin N \phi
\end{aligned}
$$

where

$$
\begin{aligned}
& \equiv \partial / \partial(k r), J_{N}(k r) \simeq \frac{1}{N !}\left(\frac{k r}{2}\right)^{N}, \\
& \text { and } y_{N}(k r) \cong-\frac{(N-1) !}{\pi}\left(\frac{2}{k r}\right)^{N}
\end{aligned}
$$

for the assumed $k r=2 \pi r / \lambda_{0} \ll<1$.

In the outer gap (subscript 3) we have fleld varlations like those of the Inner gap, 


$$
\left.\begin{array}{l}
E_{Z 3}=A_{4}\left[J_{0}(k x)-\frac{J_{0}\left(k r_{3}\right)}{Y_{0}\left(k r_{3}\right)} Y_{0}(k r)\right] \\
H_{\phi 3}=j A_{4}\left(\frac{E}{\mu}\right)^{1 / 2}\left[J_{1}(k r)-\frac{J_{0}\left(k r_{3}\right)}{Y_{0}\left(k r_{3}\right)} Y_{1}(k r)\right]
\end{array}\right\} \begin{gathered}
r_{2} \leq r \leq r_{3} \\
\text { all } \phi
\end{gathered}
$$

which constrain $E_{23}\left(r_{3}\right) \equiv 0$.

Since $N$ 1s, in practice, so large, 1.e., >10, (note that the number of vanes is $2 \mathrm{~N}$ ) the $\mathrm{Y}_{\mathrm{N}^{-}}$and $\mathrm{Y}_{\mathrm{N}}{ }^{-}$ components of the vane-gap field predominate at $I_{1}$ while the $J_{N}$ and $\mathrm{J}_{\mathrm{N}}$-components completely tominate at $I_{2}$. Hence we can match boundary conditions and determine $\mathrm{A}_{1}-\mathrm{A}_{4}$ in terms of a single vane current $I_{V}$ as reference because the inner vane region $r \leqslant 1 / 2\left(r_{1}+r_{2}\right)$ is effectively "decoupled" from the outer region $r \geq 1 / 2\left(r_{1}+r_{2}\right)$.

Assuming $I_{v} / 2$ flows through each half of a vane we have, from the fact that $\mathrm{H}_{\mathrm{r}} 2(\mathrm{r}, \phi=0)$ of Eq. $2 \mathrm{~b}$ equals $J_{v} / 2$ at each point,

$\frac{j}{\omega \nu} N A_{2} \int_{r_{1}}^{r_{2}} \frac{1}{r} \Psi_{N}(k r) d r=\frac{1}{2} I_{V}$

which determines $A_{2}$ in terms of $I_{V}$; and also

$$
\frac{1}{d \mu} \mathrm{NA}_{3} \int_{\mathrm{I}_{1}}^{\mathrm{r}_{2}} \frac{1}{\mathrm{r}} J_{\mathrm{N}}(\mathrm{kr}) \mathrm{dr} \approx \frac{1}{2} I_{V}
$$

which determines $A_{3}$. The result is these expressions far the $\overline{\mathrm{H}}$-field in each vane-gap region,

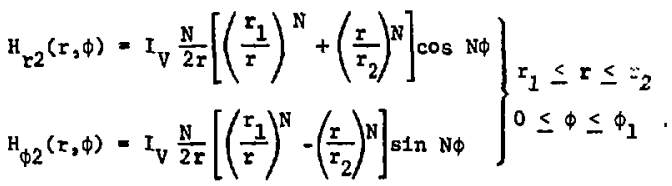

To evaluate amplitude $A_{1}$ of the 1nnergap field, (Eq. 1), we will equate the sin $N \phi-$ component of $H_{\phi 1}$ at $r_{1}$ to that apaciel component of $\mathrm{H}_{\phi 2}$ in the vare-gaps at $r_{1}$. This is the first otep in a procedure of evaluating a complete set $c$ mode amplitudes in the vane-gap region in terms of the 
amplitudes of another set in the inner gap region by multiplying ouccessively by $\sin N \phi, \sin 3 N \phi, \ldots$ and Integrating from 0 to $\phi_{1}$. The reault $1 \mathrm{~g}$, using $\mathrm{Eq} .5 \mathrm{~b}$ at $r_{1}$,

$\int_{0}^{\phi}{ }^{1} \mathrm{H}_{\phi 1}\left(\mathrm{r}_{1}\right) \sin \mathrm{N} \phi d \phi=$

$$
I_{v} \frac{N}{2 \varepsilon_{1}} \int_{0}^{\phi} 1 \sin ^{2} N \phi d \phi
$$

wh1ch yields

$$
H_{\phi 1}\left(r_{1}\right) \text {, uniform in } \phi,=I_{v} \frac{\pi N}{B r_{1}} \text {. }
$$

Know1ng that $\mathrm{H}_{\phi 1}$ varies with $\mathrm{r}$ as In Eq. Ib and has the value (Eq. 6b) at $r=r_{1}$ enables us to write, for the Inner gap regton

$$
\begin{aligned}
& H_{\phi 1}(r)= I_{v} \frac{\pi N}{8 r_{1}} \frac{J_{1}(k x)-R_{1} Y_{1}(k r)}{J_{1}\left(k r_{1}\right)-R_{1} Y_{1}\left(k r_{1}\right)}, \\
& r_{0} \leq r \leq r_{1} \\
& R_{1} \equiv J_{0}\left(k r_{0}\right) / y_{0}\left(k r_{0}\right) .
\end{aligned}
$$

By proceeding oimllarly to equate sin N申- componante of $\mathrm{H}_{\phi}$ or the $r=\mathrm{i}_{2}$ eurface we obtain $\mathrm{H}_{\phi 3}(r)$ in the outer gop region in terw of $I_{v}$ w

$$
\begin{aligned}
H_{\phi 3}(r) & =-I_{v} \frac{\pi N}{8 r_{2}} \frac{J_{1}(k r)-R_{3} Y_{1}(k r)}{J_{1}\left(k r_{2}\right)-R_{3} Y_{1}\left(k r_{2}\right)}, \\
r_{2} \leq r \leq r_{3} & (8) \\
R_{3} & \equiv J_{0}\left(k r_{3}\right) / r_{0}\left(k r_{3}\right) .
\end{aligned}
$$

We may now proceed to compare magnet $1 \mathrm{c}$ stored energies. With $Y_{0}(k r)=-\frac{2}{\pi}$ in $\frac{2}{\gamma k x}, \gamma=1.781, H_{\phi 1}$ and $H_{\phi 3}$ simplify because $k r<<1$ :

$$
H_{\phi 1}(r) \approx I_{v} \frac{\pi N}{8 r}, \quad r_{0} \leq r \leq r_{1}
$$

$\mathrm{H}_{\phi 3}(r) \simeq-I_{V} \frac{\pi \mathrm{N}}{\mathrm{Br}}, \quad r_{2} \leq r \leq r_{3}$

and we find for the time average magnetic stored energies in the gaps, $W=\frac{1}{4} \mu_{0} \int \mathrm{H}^{2} \mathrm{dv}$,

$W_{1}=\mu_{0} I_{v}^{2} \frac{\pi^{2} N^{2}}{256} \ln \frac{r_{1}}{r_{0}}$, Inper gap (10a) $W_{3}-\mu_{0} I_{v}{ }^{2} \frac{\pi^{2} v^{2}}{256} \ln \frac{r_{3}}{r_{2}}$, outer gep (10b) wh11. the stored magnetic energy $w_{2}$ In one vane-gep region is 
The magnetic energy in the entire vane region $192 \mathrm{~N}$ times this or

$W_{2}=\mu_{0} I_{v}^{2} \frac{\pi N}{32}, \quad r_{1} \leq x \leq r_{2}$.

The magnetic energy stc red in the vane region will be negligible compared to that in the inner gap if

$$
W_{2} / W_{1}=\frac{8}{\pi N \ln \frac{r_{1}}{x_{0}}} \ll 1,
$$

and $W_{2}$ will be small relitive to the energy in the outer gap if

$$
\mathrm{W}_{2} / \mathrm{W}_{3}=\frac{\mathrm{B}}{\pi \mathrm{N} \ln \frac{\mathrm{r}_{3}}{\mathrm{r}_{2}}} \ll 1 .
$$

It is interesting to note that the Inductances $L_{1}$ and $L_{3}$ agsociated with the Inner and outer gape, defined with respect to total vane current $2 \mathrm{~N} \mathbf{I}_{\mathbf{v}}$ :

$w_{1}=\frac{1}{4} L_{1}\left(2 N I_{v}\right)^{2}, w_{3}=\frac{1}{4} I_{3}\left(2 N I_{v}\right)^{2}$

eralurese of (AXS untes)

$$
\begin{aligned}
& L_{1}=0.485 \times 10^{-7} \ln \frac{r_{1}}{x_{0}} \\
& L_{3}=0.485 \times 10^{-7} \ln \frac{r_{3}}{r_{2}},
\end{aligned}
$$

wheress we would expect these answers but with coefflciente of 0.500 in the 1int of $N=\infty$. This 1 s because each gap is then like an ordinary coaxial line with an inductance per unit axtal length of $2 \times 10^{-7}$, but the magnetic field in each gap is half the total amount in the vanes, hence the inductance is one quarter the ordinary coextal line value.

If the outer gap were absent $\left(r_{2}=r_{3}\right)$ the formulas would change as Follows: $H_{\phi 1}(x)$ of Eq. 7 sould have another factor of 2 , and because $\mathrm{H}_{\mathrm{x}^{2}}\left(\mathrm{x}_{2}\right)$ of Eq. $2 \mathrm{~b}$ must be zero, Eq. S would change to

$$
H_{r 2}(r, \phi)=I_{V} \frac{N}{r}\left[\left(\frac{x_{1}}{r}\right)^{N}-\left(\frac{r_{1} r}{r_{2}{ }^{2}}\right)^{N}\right]
$$

$\cos \mathrm{N} \phi$

$$
\begin{aligned}
H_{\phi 2}(r, \phi) & =I_{V} \frac{N}{r}\left[\left(\frac{r_{1}}{r}\right)^{N}\right. \\
& \left.+\left(\frac{r_{1} r}{r_{2}}\right)^{N}\right] \sin N \phi
\end{aligned}
$$

and $w_{1}$ would quadruple whlle $w_{2}$ would only double, glviug \& $W_{2} / \omega_{2}$ rat1o only half that of Eq. 12a. The new $I_{1}$ of the inner gap region would be four times the value (Eq. 24h), whteh 12 about 37 lower than what we woulo expect as the number of vanes $2 \mathrm{~N} \rightarrow \infty$. 


\section{Appendix B}

\section{Origin of Temperature-Rise Dependence}

Assume a capacitor charges in $T$ seconds and discherges in $T$ seconds, as shown In FIg. B-1. The heat dissipated in the capacitor is proportional to $I^{2}$. Howevar, the temperature gradient depends upon the duty cycle, defined as $\frac{T}{T}$. Hence,

$$
\Delta \text { Temp } \approx\left(\frac{I^{2} T}{T}\right) .
$$

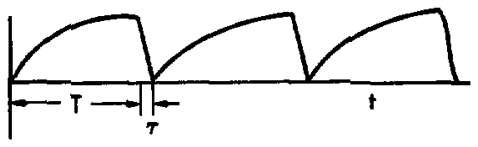

F1g. B-1. Capacitor charge and dlecharge waveforms.
We define $P_{\text {throughput }}=\frac{1}{2} \mathrm{CV}^{2} / \mathrm{T}=$ average power handled by the capacicor.

We define $P_{\text {digcharge }}=V I=$ $\frac{1}{2} C v^{2} / \mathrm{T}$.

$$
\text { Then, } \begin{aligned}
\Delta \text { Temp } & \approx\left(\frac{I^{2} \tau P_{\text {throughput }}}{\frac{1}{2} c v^{2}}\right) \\
& \approx\left(\frac{P_{\text {throughput } I^{2}}}{V I}\right) .
\end{aligned}
$$

Thus,

$$
\Delta T \operatorname{emp}=\left(\frac{P_{\text {throughput }}}{R_{d i s c h a r g e}}\right)
$$

where $R_{\text {dlscharge }}=V_{I}$.

IMM/grw 